\title{
Simultaneous Interaction of Arabidopsis thaliana with Bradyrhizobium Sp. Strain ORS278 and Pseudomonas syringae pv. tomato DC3000 Leads to Complex Transcriptome Changes
}

\author{
Fabienne Cartieaux, ${ }^{1}$ Céline Contesto, ${ }^{1}$ Adrien Gallou, ${ }^{1}$ Guilhem Desbrosses, ${ }^{1}$ Joachim Kopka, ${ }^{2}$ \\ Ludivine Taconnat, ${ }^{3}$ Jean-Pierre Renou, ${ }^{3}$ and Bruno Touraine ${ }^{1}$ \\ ${ }^{1}$ Laboratoire des Symbioses Tropicales et Méditerranéennes (UMR113, Université Montpellier 2, Institut de Recherche pour \\ le Développement, Cirad, Ecole Nationale Supérieure d'Agronomie de Montpellier, Institut National de la Recherche \\ Agronomique), Université Montpellier 2, CC 002, Place Eugène Bataillon, 34095 Montpellier Cedex 5, France; ${ }^{2}$ Max Planck \\ Institute of Molecular Plant Physiology, Am Muhlenberg 1, 14476 Golm, Germany; ${ }^{3}$ Unité de Recherche en Génomique \\ Végétale (UMR 8114 Centre National de la Recherche Scientifique, Institut National de la Recherche Agronomique, \\ Université d'Evry-Val d'Essonne), 2 rue Gaston Crémieux, CP5708-91057 Evry, France
}

Submitted 25 June 2007. Accepted 12 October 2007.

Induced systemic resistance (ISR) is a process elicited by telluric microbes, referred to as plant growth-promoting rhizobacteria (PGPR), that protect the host plant against pathogen attacks. ISR has been defined from studies using Pseudomonas strains as the biocontrol agent. Here, we show for the first time that a photosynthetic Bradyrhizobium sp. strain, ORS278, also exhibits the ability to promote ISR in Arabidopsis thaliana, indicating that the ISR effect may be a widespread ability. To investigate the molecular bases of this response, we performed a transcriptome analysis designed to reveal the changes in gene expression induced by the PGPR, the pathogen alone, or by both. The results confirm the priming pattern of ISR described previously, meaning that a set of genes, of which the majority was predicted to be influenced by jasmonic acid or ethylene, was induced upon pathogen attack when plants were previously colonized by PGPR. The analysis and interpretation of transcriptome data revealed that 12-oxo-phytodienoic acid, an intermediate of the jasmonic acid biosynthesis pathway, is likely to be an actor in the signaling cascade involved in ISR. In addition, we show that the PGPR counterbalanced the pathogeninduced changes in expression of a series of genes.

Plants of which the roots are colonized by plant growth-promoting rhizobacteria (PGPR) can develop a form of protection of both under- and above-ground parts. This type of resistance is referred to as induced systemic resistance (ISR), in order to distinguish it from the systemic acquired resistance (SAR) developed after primary infection by a pathogen (PerselloCartieaux et al. 2003). The existence of ISR was highlighted for the first time in the pathosystem Dianthus caryophyllusFusarium oxysporum sp. dianthi, whose roots were colonized by the nonpathogenic rhizobacteria Pseudomonas fluorescens WCS417r (Van Peer et al. 1991). A model based on Arabidopsis

Corresponding author: B. Touraine; Telephone: +33 4671493 53; E-mail: Bruno.Touraine@univ-montp2.fr

* The $\boldsymbol{e}$-Xtra logo stands for "electronic extra" and indicates that Figure 1 and Table 1 appear in color online. Two supplemental tables are also published online. was developed to study molecular bases of the induction of ISR by rhizobacteria (Van Loon et al. 1998). In this system, the strain Pseudomonas fluorescens WCS417r, known to induce ISR in carnation (Van Peer et al. 1991), radish (Leeman et al. 1995), tomato (Duijff et al. 1998), and Arabidopsis (Pieterse et al. 1996), was used as the protective agent. This protection is effective against various classes of pathogens, including bacterial leaf pathogens such as Pseudomonas syringae pv. tomato DC3000 and Xanthomonas campestris pv. amoracia, the fungal root pathogen Fusarium oxysporum sp. raphani, and the oomycete leaf pathogen Peronospora parasitica (Pieterse et al. 1996; Ton et al. 2002; Van Wees et al. 1997). Resistance to these pathogens appears by a delay in symptom development, a reduction of disease severity, and an inhibition of the pathogen growth. The spectrum of effectiveness of WCS417r-mediated ISR and pathogen-induced SAR overlaps but is also partly divergent (Ton et al. 2002). Moreover, the level of induced protection can be enhanced further when both ISR and SAR are activated simultaneously, indicating an additive effect of both type of resistances (Van Wees et al. 2000).

If SAR and ISR are phenotypically similar (a broad-spectrum systemic resistance), they differ by their molecular signature. The onset of SAR is unavoidably accompanied by a local and systemic increase in the endogenous level of salicylic acid (SA) (Ward et al. 1991). In contrast, ISR is independent of SA (Pieterse et al. 1996). Two types of molecular tools made it possible to precisely define the role of SA during the SAR: i) transgenic plants degrading SA (Gaffney et al. 1993) and ii) mutants unable to induce the biosynthesis of SA after an attack by a pathogen (sid1-1 and sid2-1 mutants; Nawrath and Métraux 1999). Using these mutant plants, it was also possible to show that the WCS417r-mediated ISR in Arabidopsis is independent of the accumulation of SA (Van Loon et al. 1998). On the other hand, the use of jarl-1 and etrl-1, two mutants altered in the response to jasmonic acid (JA) and ethylene (ET) respectively, indicated that WCS417r-mediated ISR requires an intact signaling pathway to these two phytohormones (Pieterse et al. 1998).

SAR is characterized by the induction of a diverse array of plant proteins, including pathogenesis-related proteins (PR), while no ISR molecular markers have been identified so far. In order to identify genes potentially involved in ISR, three large- 
scale analyses of the transcriptome have been carried out to date (Cartieaux et al. 2003; Verhagen et al. 2004; Wang et al. 2005). Two of these studies were performed without a challenging pathogen, which allowed identification of only a few defense-related genes, such as glutathione- $S$-transferase, endochitinase, or $\beta$-1,3-glucanase, to be differentially expressed in rhizobacteria-treated versus axenic plants (Cartieaux et al. 2003; Wang et al. 2005). The third analysis was designed to identify ISR-primed genes, i.e., genes of which expression was specifically modified in ISR-expressing plants that were further challenged by Pseudomonas syringae pv. tomato (Van Wees et al. 1999). The authors found 81 such ISR-primed genes among the 8,000 tested genes (one third of the Arabidopsis genome), including 19 that are responsive to JA or ET genes, or both, which confirmed the role of these two hormones throughout ISR onset.

A common point of almost all models designed so far to scrutinize plant-PGPR interactions was the use of pseudomonads or free-living nitrogen-fixing bacteria as bacterial partner. It appeared to us particularly relevant to extend the study of plant-PGPR interactions to another bacterial genus, since the question of the specificity of plant responses to different PGPR classes remains a matter of debate. The ORS278 strain is a unique photosynthetic Bradyrhizobium strain that is well-studied in our laboratory (Giraud et al. 2007). Inoculated to rice, it promotes root architecture changes together with a 10 to $20 \%$ yield increase (Chaintreuil et al. 2000). As this strain is distantly related to pseudomonads, it is an appealing candidate to check if the ability to promote ISR is universally distributed among rhizobacteria. Moreover, we wanted to test if an ORS278mediated ISR would be comparable to the one elicited by WCS417r. Therefore, we decided to conduct our work using Arabidopsis as a model system, together with Pseudomonas syringae pv. tomato as the challenge pathogen. The experimental plan designed to investigate the genome-wide expression profiling of ISR-expressing plants using CATMA microarrays (Hilson et al. 2004) included four types of samples: i) control plants in which leaves were infiltrated with sterile $\mathrm{MgSO}_{4}$, ii) plants in which roots were colonized with ORS278 and leaves infiltrated with sterile $\mathrm{MgSO}_{4}$, iii) plants in which leaves were infiltrated with pathogens, and iv) plants in which roots were colonized with ORS278 and leaves infiltrated with pathogens. Five cross-hybridizations were realized on CATMA slides: plants in group i crossed with those in ii, iii, or iv, and those in group iv crossed with those in groups ii or iii. The results indicate that a component of the oxylipin biosynthesis pathway was involved in ISR onset. Furthermore, this study revealed that rhizospheric Bradyrhizobium sp. strain ORS278 alleviated transcriptional changes induced by leaf-inoculated $P$. syringae pv. tomato DC3000, in particular the induction of defenserelated genes and the repression of photosynthesis genes.

\section{RESULTS}

Bradyrhizobium-mediated ISR against $P$. syringae.

The dry weight of shoots of in vitro two-week-old Arabidopsis plants measured one week after Bradyrhizobium sp. strain ORS278 inoculation (an average of $0.329 \mathrm{mg}$ per shoot, $n=18)$ was significantly greater than in control plants $(0.259$ mg per shoot, $n=18$ ). Therefore, Bradyrhizobium sp. strain ORS278 appears to promote Arabidopsis growth similarly to what has been shown in rice (Chaintreuil et al. 2000).

Since the protection against pathogens has been reported to be a core component of plant growth-promoting ability of PGPR (Persello-Cartieaux et al. 2003), we tested the protective property of Bradyrhizobium sp. strain ORS278 by challenging the bacterized Arabidopsis with P. syringae pv. tomato DC3000, a bacterial pathogen causing leaf speck disease on Arabidopsis (Whalen et al. 1991). Seven days after infection with P. syringae, control plants displayed severe disease symptoms (Fig. 1A). In contrast, plants in which roots had previously been colonized by Bradyrhizobium sp. strain ORS278 showed necrotic lesions that resemble those induced during incompatible plant-pathogen interactions. Consistent with this observation, the treatment with Bradyrhizobium sp. strain ORS278 resulted in inhibition of growth of $P$. syringae by up to sevenfold on day 4 after inoculation as compared with control plants (Fig. $1 \mathrm{~B})$. In the culture conditions used in this experiment, there was no significant difference between the shoot fresh weights of ORS278-protected and control plants $(85 \pm 31$ and $78 \pm 29$ $\mathrm{mg}$ of FW, respectively) and the leaf numbers of either type of plant $(11.0 \pm 0.9$ and $10.7 \pm 1.1$, respectively). Therefore, the ORS278-induced resistance cannot be attributed to a developmentally regulated process, such as the age-related resistance described elsewhere (Murphy et al. 2003). Overall, our results thus indicate that Bradyrhizobium sp. strain ORS278 has the ability to induce effective systemic resistance against infection with $P$. syringae pv. tomato DC 3000.

\section{Metabolite fingerprinting experiments demonstrate minor within-replicate sample variability compared with predominant between-treatment variation.}

Metabolomics can be used to profile and identify marker metabolites, which change in pool size upon treatments (metabolite profiling) (Broeckling et al. 2005; Colebatch et al. 2004; Desbrosses et al. 2005). In addition, this approach is highly useful for assessing within-replicate variability compared

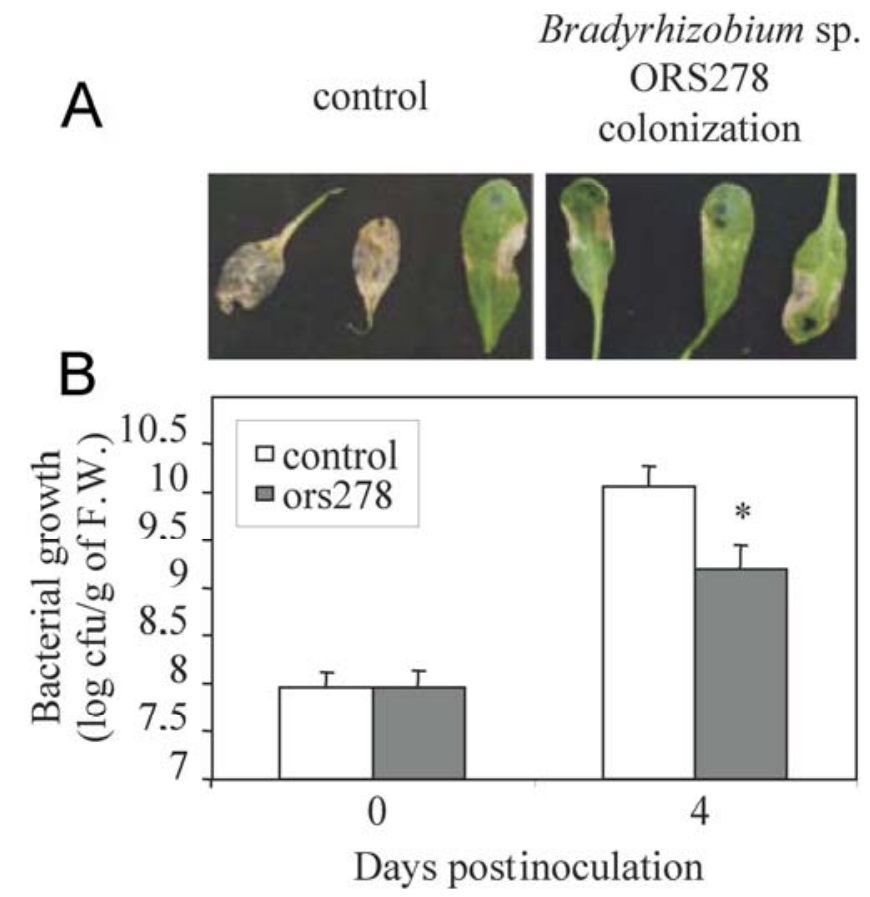

Fig. 1. Bradyrhizobium sp. strain ORS278 colonization triggered effective systemic resistance against challenge infection of Pseudomonas syringae pv. tomato DC3000 in Arabidopsis plants. A, Disease symptoms on plants 7 days after inoculation with $P$. syringae pv. tomato DC3000. B, In planta growth of $P$. syringae pv. tomato DC3000 in control and ORS278-inoculated plants. Concentrations of bacteria in leaves of control (open bars) and ISR-expressing plants (gray bars) were assayed 0 and 4 days after manual infiltration with a $2 \times 10^{5} \mathrm{CFU} / \mathrm{ml}$ suspension. Data points are means (CFU/g) with standard errors from 30 infected leaves. The asterisk indicates statistically significant differences between treatments (Student's $t$ test, $\alpha \leq 0.05$ ). Similar results (data not shown) were obtained in a second and third independent experiments. 
with the metabolic differences induced by experimental treatments (Fiehn 2004). These metabolic changes are in part correlated and in part complementary to transcriptional changes (Gibon et al. 2004; Urbanczyk-Wochniak et al. 2005). Thus, we used metabolite fingerprinting as a highly versatile and sensitive tool to evaluate the homogeneity of the biological replications of the present study.

Since this experiment had been designed to identify genes involved in the onset of ORS278-mediated ISR, our samples consisted of ISR-expressing plants challenged by $P$. syringae pv. tomato DC3000. Infected leaves were collected $24 \mathrm{~h}$ after infection by the pathogen. Gas chromatographic-electrospray ionization-time of flight-mass spectrometry (GC-EI-TOF-MS)based metabolite fingerprints were performed on each of the samples issued from three leaves harvested on three different plants obtained through three independent cultures corresponding to three independent biotic treatments. The GC-MS-based metabolite fingerprinting and data normalization was essentially performed as described by Desbrosses and associates (2005) and was applied to all available nonpooled independent replications comprising nine replications per biological treatment (Supplementary Table 1). We performed two independent statistical approaches for sample classification. Hierarchical clustering analysis (HCA)-based Euclidian distance clearly demonstrated unambiguous classification of replicate samples into separate branches of the clustering tree (Fig. 2). No missorting was observed. However, because missing value substitution and manual elimination of mass fragments representing laboratory contaminations or internal standards may bias clustering analyses, we performed an alternative investigation. Independent component analysis (ICA) in combination with applying analysis of variance (ANOVA) for filtering nonrelevant mass fragments confirmed our initial finding. In addition, it demon-

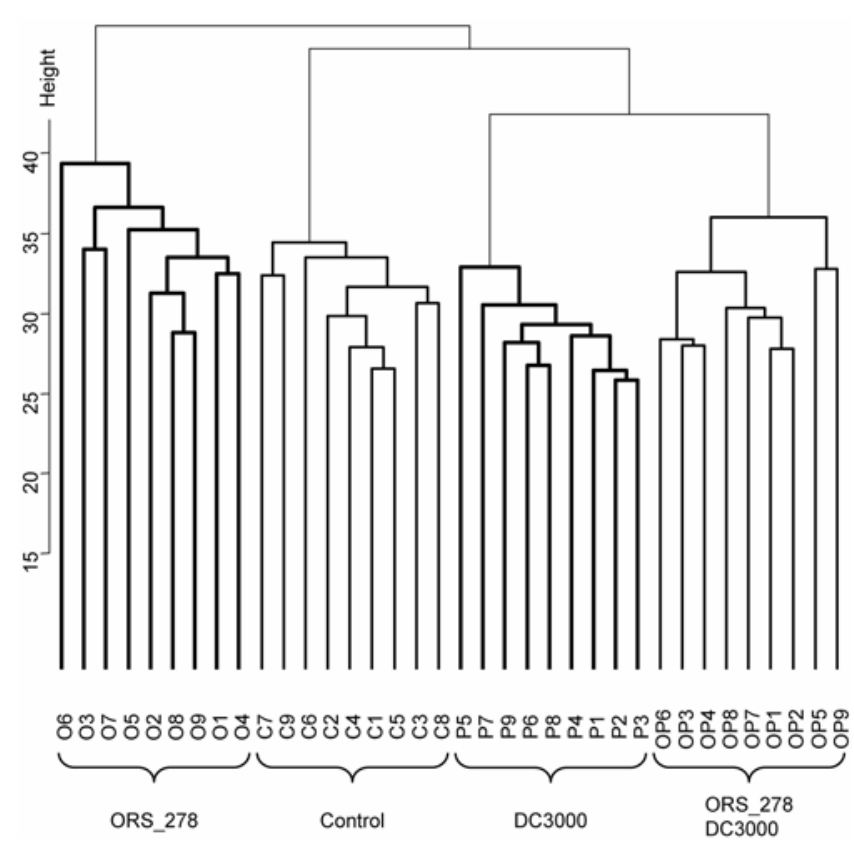

Fig. 2. Hierarchical cluster analysis of polar extracts from leaves of Arabidopsis thaliana. Profiles were generated from i) control plants in which leaves were infiltrated with sterile $\mathrm{MgSO}_{4}$ solution (control), ii) plant growth-promoting rhizobacteria plants cocultivated with Bradyrhizobium sp. strain ORS278 and infiltrated with sterile $\mathrm{MgSO}_{4}$ solution (ORS278), iii) induced systemic resistance plants cocultivated with Bradyrhizobium sp. strain ORS278 and infiltrated with a $2 \times 10^{5} \mathrm{CFU} / \mathrm{ml}$ suspension of Pseudomonas syringae pv. tomato DC3000 (ORS278/DC3000), and iv) control plants in which leaves were infiltrated with a $2 \times 10^{5} \mathrm{CFU} / \mathrm{ml}$ suspension of $P$. syringae pv. tomato DC3000 (DC3000). strated that the between-treatment variation was higher than the experimental error, as estimated by nine independent replications (Fig. 3).

In planta pathogen growth was not significantly different in ORS278-protected and control plants at this timepoint $(7.93 \pm$ 0.53 and $7.49 \pm 0.32 \log \mathrm{CFU} \mathrm{g} \mathrm{g}^{-1} \mathrm{FW}$ respectively). Therefore, the metabolite profiling modifications observed are most likely related to PGPR response rather than to a modulation of the pathogen response. From the statistical analyses performed, we concluded that our experiment consisted of three validated biological repeats, and we decided to pool the samples within each biological treatment for our transcriptome analysis.

\section{Transcript profiling of Arabidopsis plants colonized by ISR-inducing Bradyrhizobium sp. strain ORS278.}

Since the biological replications were highly homogeneous, we pooled the nine biological samples corresponding to each treatment. Total RNA prepared from these pooled leaf samples collected from control and treated plants were then analyzed using the CATMA chips. The CATMA project (complete Arabidopsis transcriptome microarray) provides the Arabidopsis scientific community with a generic array to address all biological questions concerning this species. The current version of CATMA contains 24,576 probes, representing about $85 \%$ of the genes predicted by Eugene (Foissac et al. 2003). The probes are 'gene sequence tags' (GST) designed with specific primers and amplicons design software (Thareau et al. 2003).

Genes with differential expression were selected by statistical analysis, using a $P$ value cut-off of less than 0.05 after Bonferroni correction. We chose to focus on genes with a Bonferroni $P$ value $\leq 6.10^{-6}$, corresponding to an average of fold changes (treated plants/control) in expression level greater than 1 or less than -1 (results are given as $\log _{2}$ ) (Table 1). We were not able to detect genes whose expression was up-regulated by Bradyrhizobium sp. strain ORS278 except for the defensin PDF 1,1. In contrast, 203 genes were down-regulated by the presence of Bradyrhizobium sp. strain ORS278 (Supplementary Table 2). Of these genes $38 \%$ are annotated as 'unclassified proteins,' $19 \%$

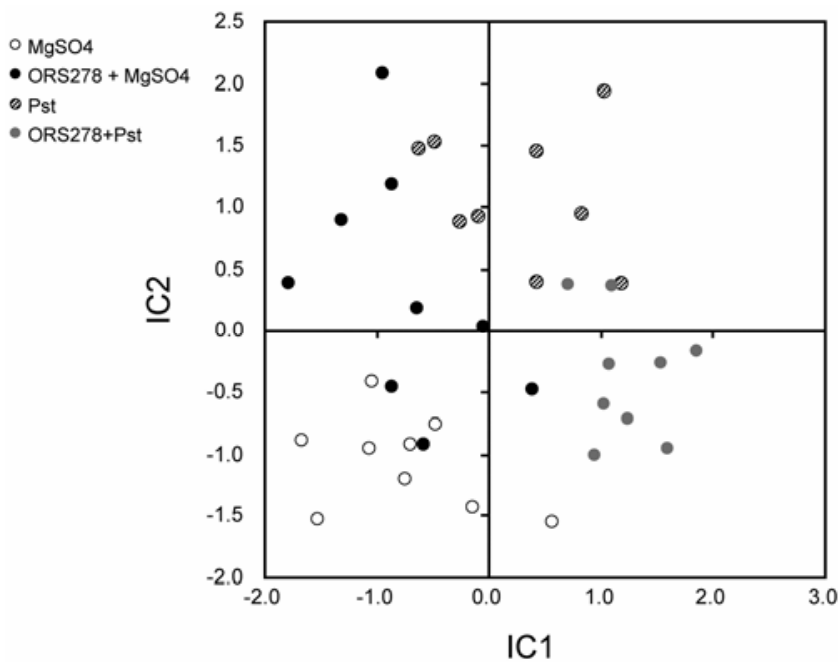

Fig. 3. Independent component analysis of polar extracts from leaves of Arabidopsis thaliana. Profiles were generated from i) control plants in which leaves were infiltrated with sterile $\mathrm{MgSO}_{4}$ solution $\left(\mathrm{MgSO}_{4}\right)$, ii) plant growth-promoting rhizobacteria plants cocultivated with Bradyrhizobium sp. strain ORS278 and infiltrated with sterile $\mathrm{MgSO}_{4}$ solution (ORS278 $+\mathrm{MgSO}_{4}$ ), iii) ISR plants cocultivated with Bradyrhizobium sp. strain ORS278 and infiltrated with a $2 \times 10^{5} \mathrm{CFU} / \mathrm{ml}$ suspension of Pseudomonas syringae pv. tomato DC3000 (ORS278 + P. syringae pv. tomato), and iv) control plants in which leaves were infiltrated with a $2 \times 10^{5}$ CFU/ml suspension of $P$. syringae pv. tomato DC3000 (Pst). 


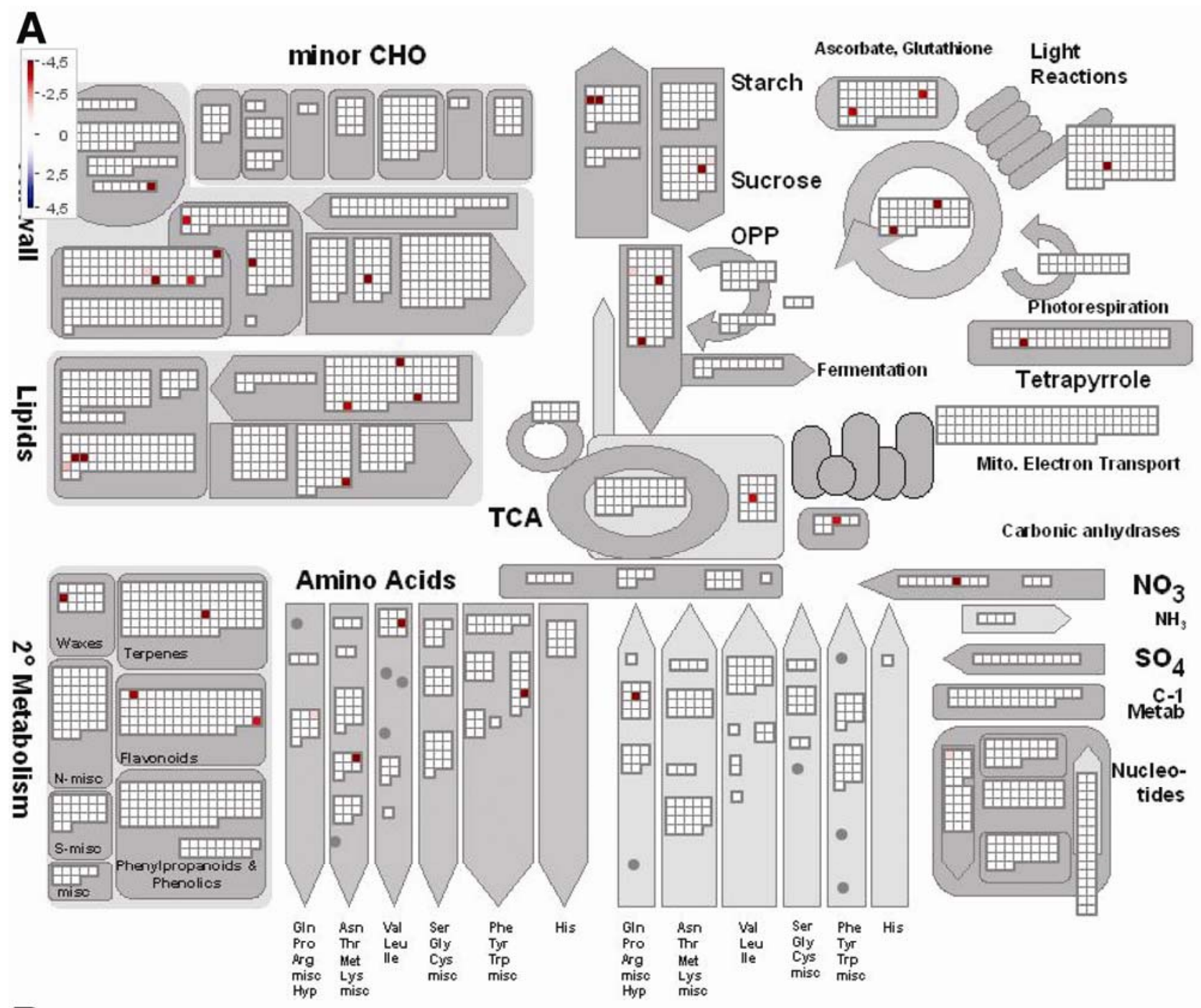

B

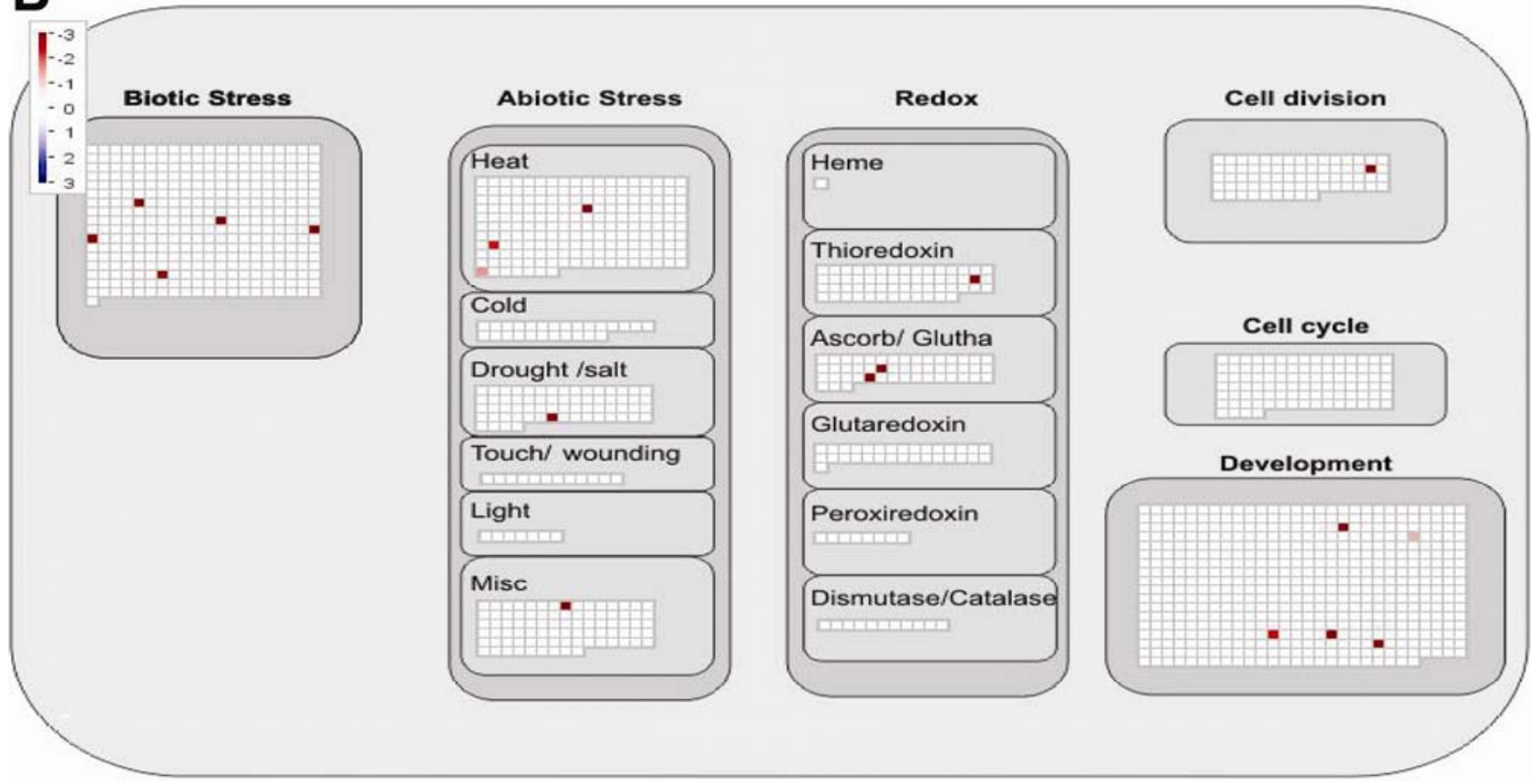

Fig. 4. Impact of Bradyrhizobium sp. strain ORS278 on its host metabolism. A, The MapMan Metabolism overview display created using the 203 Bradyrhizobium sp. strain ORS278-regulated genes identified from the plant growth-promoting rhizobacteria versus control comparison. B, The MapMan cellular response overview display created using the same pool of genes. The fold change is displayed as illustrated in the fold change color bar in the upper left of each panel (red is repressed, blue is induced). 
are predicted to be involved in metabolism, $12 \%$ in cellular transport, $10 \%$ in signal transduction, $5 \%$ in protein metabolism, $3 \%$ in regulation of transcription, $3 \%$ in cell wall modification, and 3\% in defense response. Among all the Bradyrhizobium sp. strain ORS278-responsive genes, a gene coding for an aconitase (enzyme involved in the Krebs' cycle) was observed as the most strongly repressed (i.e., sevenfold). To draw a comprehensive overview of the cellular and metabolism responses of Arabidopsis, we took advantage from the Mapman toolbox developed by Thimm and coworkers (2004). The MapMan overview metabolism map highlights the fact that genes involved in biotic and abiotic stress are down-regulated (Fig. 4).

An earlier transcriptome analysis showed no detectable increase in transcript level associated to ISR (Verhagen et al. 2004). However, the same study highlighted a set of 30 genes whose expression was modified after $P$. syringae pv. tomato DC3000 challenge in ISR-expressing plants but not when plants were challenged only by the pathogen. The authors referred to these genes as primed ISR-specific. We observed the same priming pattern in our set of experiments: 64 genes showed an increased level of transcription in ISR-expressing plants after pathogen attack as compared with that in control plants (Table
1, Figs. 5B and D). The majority of the 64 primed ISR-specific genes belonged to the following functional categories: metabolism $(23 \%)$, defense response $(11 \%)$, regulation of transcription (9\%), signal transduction (9\%), and cellular transport $(6 \%)$. Among the seven genes annotated as 'defense response,' $P D F 1.1$, a putative defensin, was overexpressed in response to Bradyrhizobium sp. strain ORS278 colonization independently of pathogen attack. This is the only gene that showed an upregulation of its transcription after Bradyrhizobium sp. strain ORS278 colonization among the approximately 22,000 genes represented on the CATMA array. In addition to the seven primed ISR-specific genes annotated as 'defense response,' three genes annotated as 'metabolism' (AT1G19670, AT4G16260, AT5G05730) have been reported to be induced by jasmonate, which tends to demonstrate that they could be involved in response to wounding or pathogen attack. Seven transcription factors annotated as 'regulation of transcription' are all involved in response to biotic or abiotic stresses, and five of them are actually related to response to wounding or pathogen attacks. Other genes related to elevated disease resistance could be genes coding for heat shock proteins (AT3G09440, AT5G02500) and the PEN3/PDR8 ATP-binding

Table 1. Fold-change ratios of induced systemic resistance (ISR)-primed Pseudomonas syringae pv. tomato DC3000-responsive genes in leaves of Bradyrhizobium ORS278-treated plants ${ }^{\mathrm{a}}$

\begin{tabular}{|c|c|c|c|c|c|c|c|}
\hline \multirow[b]{2}{*}{ AGI name } & \multirow[b]{2}{*}{ Function TIGR } & \multicolumn{2}{|c|}{ ORS278 } & \multicolumn{2}{|c|}{$\begin{array}{l}\text { ORS278-Pseudomonas } \\
\text { syringae pv. } \\
\text { tomato/control }\end{array}$} & \multicolumn{2}{|c|}{$\begin{array}{l}\text { Pseudomonas syringae } \\
\text { pv. tomato/control }\end{array}$} \\
\hline & & Fold-change & $P$-value & Fold-change & $P$-value & Fold-change & $P$-value \\
\hline \multicolumn{8}{|c|}{ Defense response } \\
\hline AT1G75830 & Plant defensin-fusion protein, putative (PDF1.1) & 1.50 & $\mathbf{0 . 0 0 E}+\mathbf{0}$ & 1.63 & $0.0 \mathrm{E}+00$ & -1.53 & $0.00 \mathrm{E}+0$ \\
\hline AT2G37040 & Phenylalanine ammonia-lyase 1 (PAL1) & -0.54 & $1.00 \mathrm{E}+0$ & 1.36 & $0.0 \mathrm{E}+00$ & -0.13 & $1.00 \mathrm{E}+0$ \\
\hline AT3G26200 & Cytochrome P450 71B22, putative (CYP71B22) & 0.50 & $1.00 \mathrm{E}+0$ & 1.44 & $0.0 \mathrm{E}+00$ & 0.50 & $1.00 \mathrm{E}+0$ \\
\hline AT4G19120 & Early-responsive to dehydration stress protein (ERD3) & -0.96 & $9.98 \mathrm{E}-5$ & 1.02 & $3.5 \mathrm{E}-06$ & -0.59 & $1.00 \mathrm{E}+0$ \\
\hline AT4G23100 & Gamma-glutamylcysteine synthetase (GSH1) & -1.50 & $0.00 \mathrm{E}+0$ & 1.35 & $0.0 \mathrm{E}+00$ & 0.28 & $1.00 \mathrm{E}+0$ \\
\hline AT5G40170 & Disease resistance family protein & -1.07 & $1.21 \mathrm{E}-6$ & 1.34 & $0.0 \mathrm{E}+00$ & -0.29 & $1.00 \mathrm{E}+0$ \\
\hline AT5G45340 & Cytochrome P450 family protein & 0.15 & $1.00 \mathrm{E}+0$ & 1.08 & $1.9 \mathrm{E}-07$ & 0.69 & $5.59 \mathrm{E}-1$ \\
\hline \multicolumn{8}{|l|}{ Metabolism } \\
\hline AT1G03310 & $\begin{array}{l}\text { Isoamylase, putative/starch debranching enzyme, } \\
\text { putative }\end{array}$ & -0.66 & $1.00 \mathrm{E}+0$ & 1.01 & $4.7 \mathrm{E}-06$ & -0.46 & $1.00 \mathrm{E}+0$ \\
\hline AT1G19670 & Coronatine-responsive protein (COR1) & 0.59 & $1.00 E+0$ & 1.39 & $0.0 \mathrm{E}+00$ & -0.26 & $1.00 E+0$ \\
\hline AT1G50480 & 10-formyltetrahydrofolate synthetase (THFS) & -1.56 & $0.00 \mathrm{E}+0$ & 1.09 & $1.3 \mathrm{E}-7$ & -0.82 & $1.21 \mathrm{E}-2$ \\
\hline AT2G16500 & Arginine decarboxylase 1 (SPE1) (ARGDC) & -2.14 & $0.00 \mathrm{E}+0$ & 1.23 & $2.2 \mathrm{E}-10$ & -0.28 & $1.00 \mathrm{E}+0$ \\
\hline AT2G29630 & $\begin{array}{l}\text { Thiamine biosynthesis family protein/thiC family } \\
\text { protein }\end{array}$ & -3.91 & $0.00 \mathrm{E}+0$ & 1.57 & $0.0 \mathrm{E}+00$ & -1.69 & $0.00 \mathrm{E}+0$ \\
\hline AT3G13750 & Beta-galactosidase, putative/lactase, putative & -0.04 & $1.00 \mathrm{E}+0$ & 1.04 & $1.4 \mathrm{E}-06$ & -0.04 & $1.00 \mathrm{E}+0$ \\
\hline AT3G46970 & Starch phosphorylase, putative & -2.85 & $0.00 \mathrm{E}+0$ & 1.22 & $4.3 \mathrm{E}-10$ & -1.19 & $1.00 \mathrm{E}-8$ \\
\hline AT3G48560 & Acetolactate synthase, chloroplast (ALS) & -1.74 & $0.00 \mathrm{E}+0$ & 1.12 & $3.1 \mathrm{E}-08$ & -0.43 & $1.00 \mathrm{E}+0$ \\
\hline AT3G55410 & Oxoglutarate decarboxylase, putative & -0.04 & $1.00 \mathrm{E}+0$ & 1.05 & $9.2 \mathrm{E}-07$ & -0.16 & $1.00 \mathrm{E}+0$ \\
\hline AT4G04610 & PAPS reductase homolog (PRH19) & -2.46 & $0.00 \mathrm{E}+0$ & 1.04 & $1.4 \mathrm{E}-06$ & -0.06 & $1.00 \mathrm{E}+0$ \\
\hline AT4G16260 & Glycosyl hydrolase family 17 protein & -0.18 & $1.00 \mathrm{E}+0$ & 1.45 & $0.0 \mathrm{E}+00$ & 0.68 & $7.52 \mathrm{E}-1$ \\
\hline AT5G04590 & Sulfite reductase/ferredoxin (SIR) & -1.59 & $0.00 \mathrm{E}+0$ & 1.08 & $2.2 \mathrm{E}-07$ & -0.62 & $1.00 \mathrm{E}+0$ \\
\hline AT5G05730 & Anthranilate synthase, alpha subunit (ASA1) & -1.32 & $1.12 \mathrm{E}-11$ & 1.99 & $0.0 \mathrm{E}+00$ & 0.49 & $1.00 E+0$ \\
\hline AT5G42270 & Ftsh protease, putative & -0.61 & $1.00 \mathrm{E}+0$ & 1.12 & $3.8 \mathrm{E}-08$ & -0.37 & $1.00 \mathrm{E}+0$ \\
\hline AT5G49720 & Endo-1,4-beta-glucanase KORRIGAN (KOR) & -2.63 & $0.00 \mathrm{E}+0$ & 1.19 & $1.6 \mathrm{E}-09$ & -0.57 & $1.00 \mathrm{E}+0$ \\
\hline \multicolumn{8}{|l|}{ Protein folding } \\
\hline AT3G09440 & Heat shock cognate $70 \mathrm{kDa}$ protein 3 (HSC70-3) & -3.27 & $0.00 \mathrm{E}+0$ & 1.9 & $0.0 \mathrm{E}+00$ & -0.18 & $1.00 \mathrm{E}+0$ \\
\hline AT5G02500 & Heat shock cognate $70 \mathrm{kDa}$ protein 1 (HSC70-1) & -1.26 & $2.57 \mathrm{E}-10$ & 1.40 & $0.0 \mathrm{E}+00$ & 0.05 & $1.00 \mathrm{E}+0$ \\
\hline AT5G42020 & Luminal binding protein $2(\mathrm{BiP}-2)(\mathrm{BP} 2)$ & -4.49 & $0.00 \mathrm{E}+0$ & 1.23 & $1.7 \mathrm{E}-10$ & -0.58 & $1.00 \mathrm{E}+0$ \\
\hline
\end{tabular}

DNA metabolism

$\begin{array}{ll}\text { AT2G42520 } & \text { DEAD box RNA helicase, putative } \\ \text { AT5G08610 } & \text { DEAD box RNA helicase (RH26) }\end{array}$

Signal transduction

AT1G03740 Protein kinase family protein

AT1G15690 Pyrophosphate-energized inorganic pyrophosphatase

AT1G73500 Mitogen-activated protein kinase kinase (MAPKK)

\begin{tabular}{lll|lll}
\hline-0.63 & $1.00 \mathrm{E}+0$ & 1.06 & $5.9 \mathrm{E}-07$ & -0.15 & $1.00 \mathrm{E}+0$ \\
\hline-1.79 & $0.00 \mathrm{E}+0$ & 1.73 & $0.0 \mathrm{E}+00$ & -0.82 & $1.36 \mathrm{E}-2$ \\
\hline
\end{tabular}

\footnotetext{
a Plants were four weeks old and all samples used for RNA extraction were collected $24 \mathrm{~h}$ after infection. Genes in which expression has been confirmed by real-time polymerase chain reaction are indicated in bold.
} 
cassette transporter involved in nonhost resistance (AT1G59870; Stein et al. 2006). Finally, altogether, genes potentially involved in elevated disease resistance represent $24 \%$ of the primed ISR-specific genes found in our PGPR pathosystem.

The MapMan overview maps show that inoculation with ORS 278 resulted in decreased responsiveness of overall gene expression changes triggered by $P$. syringae pv. tomato DC3000 attack (Fig. 5A and C as compared with B and D).

\section{Quantitative polymerase chain reaction (qPCR) analysis} of representative primed ISR-specific genes.

To validate the results obtained with the CATMA microarray, the expression pattern of seven clones (AT1G75830, AT2G37040, AT1G19670, AT4G16260, AT5G05730, AT1G27730, and AT1G59870), selected on the basis of their ISR-specific upregulation, was further analyzed by qPCR (Fig. 6). For this purpose, RNA extracted from untreated and treated plants from three independent biological experiments were analyzed independently. For six genes tested (ABC transporter [AT1G59870], AtCLH1, ZAT10, PAL1, $\beta 1.3$ glucanase [AT4G16260], and $A S A 1)$, the analysis performed fully confirmed the results obtained in the DNA microarray hybridization experiments, i.e., an increased expression in plants expressing ISR after pathogen attack (primed ISR-specific genes). On the contrary, the upregulation of the PDF1.1 gene following Bradyrhizobium sp. strain ORS278 colonization observed with the CATMA microarrays was not confirmed by qPCR analysis (Fig. 6B). As PDF1.1 belongs to a multigene family, we suspected that this discrepancy could be due to a nonspecific hybridization of cDNAs of other members of the family on CATMA microarrays. This possibility has been highlighted by CATMA GST designers through a code used to classify GST according to their quality and available on FLAGdb database (Samson et al. 2004). In order to test this hypothesis of a cross-hybridization, we aligned the sequence of the PDF1.1 gene-specific sequence tag (GSTpdf1.1) spotted on CATMA microarrays against the sequences of PDF1.1, PDF1.2a, PDF1.2b, PDF1.2c, and PDF1.3 (Fig. 7). The six sequences shared a 40-bp consensus, which could lead to a nonspecific hybridization of $P D F 1.2 a$, PDF1.2b, PDF 1.2c, and PDF1.3 cDNAs on GSTpdf1.1. To clearly identify the genes whose expression was induced by Bradyrhizobium sp. strain ORS278, we designed specific pairs of primers for the seven members of the PDF1 family (Table 2 ). The results of the qPCR analyses performed with those

Table 1. Continued from preceding page

\begin{tabular}{|c|c|c|c|c|c|c|c|}
\hline \multirow[b]{2}{*}{ AGI name } & \multirow[b]{2}{*}{ Function TIGR } & \multicolumn{2}{|c|}{ ORS278 } & \multicolumn{2}{|c|}{$\begin{array}{c}\text { ORS278-Pseudomonas } \\
\text { syringae pv. } \\
\text { tomato/control }\end{array}$} & \multicolumn{2}{|c|}{$\begin{array}{l}\text { Pseudomonas syringae } \\
\text { pv. tomato/control }\end{array}$} \\
\hline & & Fold-change & $P$-value & Fold-change & $P$-value & Fold-change & $P$-value \\
\hline \multicolumn{8}{|c|}{ Signal transduction (Continued) } \\
\hline AT1G79680 & Wall-associated kinase, putative & -0.38 & $1.00 \mathrm{E}+0$ & 1.08 & $2.1 \mathrm{E}-07$ & 0.86 & $4.40 \mathrm{E}-3$ \\
\hline AT3G45860 & Receptor-like protein kinase, putative & -1.31 & $1.68 \mathrm{E}-11$ & 1.26 & $5.6 \mathrm{E}-11$ & -0.25 & $1.00 \mathrm{E}+0$ \\
\hline AT4G00720 & $\begin{array}{l}\text { Shaggy-related protein kinase theta/ASK-theta } \\
\text { (ASK8) }\end{array}$ & -1.66 & $0.00 \mathrm{E}+0$ & 1.21 & $4.3 \mathrm{E}-10$ & -0.03 & $1.00 \mathrm{E}+0$ \\
\hline \multicolumn{8}{|c|}{ Ubiquitin-dependent protein catabolism } \\
\hline AT1G68050 & F-box family protein (FKF1)/adagio 3 (ADO3) & -1.15 & $2.96 \mathrm{E}-8$ & 1.05 & $7.2 \mathrm{E}-07$ & -0.31 & $1.00 \mathrm{E}+0$ \\
\hline AT2G25490 & F-box family protein (FBL6) & -1.02 & $1.00 \mathrm{E}-5$ & 2.26 & $0.0 \mathrm{E}+00$ & -0.09 & $1.00 \mathrm{E}+0$ \\
\hline AT5G15400 & U-box domain-containing protein & -0.21 & $1.00 \mathrm{E}+0$ & 1.22 & 2.9E-10 & -0.06 & $1.00 \mathrm{E}+0$ \\
\hline \multicolumn{8}{|c|}{ Regulation of transcription } \\
\hline AT1G27730 & Zinc finger (C2H2 type) family protein (ZAT10) & 0.04 & $1.00 \mathrm{E}+0$ & 1.21 & $4.6 \mathrm{E}-10$ & 0.44 & $1.00 E+0$ \\
\hline AT1G68840 & AP2 domain-containing protein RAP2,8 & 0.76 & $7.56 \mathrm{E}-2$ & 1.29 & $5.6 \mathrm{E}-12$ & -0.04 & $1.00 \mathrm{E}+0$ \\
\hline AT4G23810 & WRKY53 family transcription factor & 0.47 & $1.00 \mathrm{E}+0$ & 1.04 & $1.2 \mathrm{E}-06$ & 0.23 & $1.00 \mathrm{E}+0$ \\
\hline AT4G36990 & Heat shock transcription factor 4 (HSTF4) & -0.57 & $1.00 \mathrm{E}+0$ & 1.01 & $4.6 E-06$ & 0.56 & $1.00 \mathrm{E}+0$ \\
\hline AT5G04340 & Zinc finger (C2H2 type) family protein & 0.24 & $1.00 \mathrm{E}+0$ & 1.00 & $6.0 \mathrm{E}-06$ & -0.10 & $1.00 \mathrm{E}+0$ \\
\hline AT5G67450 & Zinc finger ( $\mathrm{C} 2 \mathrm{H} 2$ type) protein $1(\mathrm{AZF} 1)$ & 0.54 & $1.00 \mathrm{E}+0$ & 1.07 & $3.8 \mathrm{E}-07$ & 0.41 & $1.00 \mathrm{E}+0$ \\
\hline \multicolumn{8}{|c|}{ Cellular transport } \\
\hline AT1G59870 & ABC transporter family protein & -2.67 & $0.00 \mathrm{E}+\mathbf{0}$ & 1.82 & $0.0 E+00$ & -0.13 & $1.00 \mathrm{E}+0$ \\
\hline AT2G21390 & Coatomer protein complex, subunit alpha, putative & -0.04 & $1.00 \mathrm{E}+0$ & 1.09 & $1.3 \mathrm{E}-07$ & -0.09 & $1.00 \mathrm{E}+0$ \\
\hline AT2G22500 & Mitochondrial substrate carrier family protein & 0.29 & $1.00 \mathrm{E}+0$ & 1.36 & $0.0 \mathrm{E}+00$ & -0.16 & $1.00 \mathrm{E}+0$ \\
\hline AT2G46430 & Cyclic nucleotide-regulated ion channel (CNGC3) & -1.61 & $0.00 \mathrm{E}+0$ & 1.05 & $8.4 \mathrm{E}-07$ & -0.07 & $1.00 \mathrm{E}+0$ \\
\hline \multicolumn{8}{|c|}{ Unclassified protein } \\
\hline AT1G43690 & Ubiquitin interaction motif-containing protein & -1.51 & $0.00 \mathrm{E}+0$ & 1.05 & $7.8 \mathrm{E}-07$ & -0.25 & $1.00 \mathrm{E}+0$ \\
\hline AT1G51980 & $\begin{array}{l}\text { Mitochondrial processing peptidase alpha subunit, } \\
\text { putative }\end{array}$ & -1.89 & $0.00 \mathrm{E}+0$ & 1.28 & $1.7 \mathrm{E}-11$ & 0.02 & $1.00 \mathrm{E}+0$ \\
\hline AT1G70700 & Expressed protein & 0.06 & $1.00 \mathrm{E}+0$ & 1.66 & $0.0 \mathrm{E}+00$ & 0.32 & $1.00 \mathrm{E}+0$ \\
\hline AT1G79600 & ABC1 family protein & -0.30 & $1.00 \mathrm{E}+0$ & 1.03 & $2.3 \mathrm{E}-06$ & -0.17 & $1.00 \mathrm{E}+0$ \\
\hline AT2G20960 & Expressed protein & -1.00 & $1.73 E-5$ & 1.56 & $0.0 \mathrm{E}+00$ & 0.23 & $1.00 \mathrm{E}+0$ \\
\hline AT2G31460 & Hypothetical protein & -3.61 & No & 1.36 & $0.0 \mathrm{E}+00$ & -0.52 & $1.00 \mathrm{E}+0$ \\
\hline AT2G40000 & Expressed protein & -0.32 & $1.00 \mathrm{E}+0$ & 1.38 & $0.0 \mathrm{E}+00$ & 0.49 & $1.00 \mathrm{E}+0$ \\
\hline AT2G45220 & Pectinesterase family protein & -1.89 & $0.00 \mathrm{E}+0$ & 1.27 & $3.4 \mathrm{E}-11$ & 0.07 & $1.00 \mathrm{E}+0$ \\
\hline AT3G07700 & ABC1 family protein & -2.27 & $0.00 \mathrm{E}+0$ & 1.24 & $1.1 \mathrm{E}-10$ & -0.14 & $1.00 \mathrm{E}+0$ \\
\hline AT3G09020 & Alpha 1,4-glycosyltransferase family protein & -0.03 & $1.00 \mathrm{E}+0$ & 1.04 & $1.5 \mathrm{E}-06$ & 0.26 & $1.00 \mathrm{E}+0$ \\
\hline AT3G19030 & Expressed protein & 0.93 & $2.76 \mathrm{E}-4$ & 1.27 & $3.4 \mathrm{E}-11$ & 0.15 & $1.00 \mathrm{E}+0$ \\
\hline AT3G27260 & DNA-binding bromodomain-containing protein & -0.55 & $1.00 \mathrm{E}+0$ & 1.12 & $4.5 \mathrm{E}-08$ & -0.36 & $1.00 \mathrm{E}+0$ \\
\hline AT3G33004 & $\begin{array}{l}\text { Pseudogene, DNA-directed RNA polymerase beta- } \\
\text { chain }\end{array}$ & -0.07 & $1.00 \mathrm{E}+0$ & 1.08 & $2.1 \mathrm{E}-07$ & -0.41 & $1.00 \mathrm{E}+0$ \\
\hline AT3G48650 & Pseudogene, At14a-related protein & -0.19 & $1.00 \mathrm{E}+0$ & 1.56 & $0.0 \mathrm{E}+00$ & 0.55 & $1.00 \mathrm{E}+0$ \\
\hline AT3G60750 & Transketolase, putative & -3.15 & $0.00 \mathrm{E}+0$ & 2.06 & $0.0 \mathrm{E}+00$ & -1.50 & $0.00 \mathrm{E}+0$ \\
\hline AT4G12290 & Copper amine oxidase, putative & -1.97 & $0.00 \mathrm{E}+0$ & 1.41 & $0.0 \mathrm{E}+00$ & -0.39 & $1.00 \mathrm{E}+0$ \\
\hline AT4G32020 & Expressed protein & -0.30 & $1.00 \mathrm{E}+0$ & 1.13 & $2.3 \mathrm{E}-08$ & -0.14 & $1.00 \mathrm{E}+0$ \\
\hline AT4G38770 & Proline-rich family protein (PRP4) & -1.30 & $2.80 \mathrm{E}-11$ & 1.54 & $0.0 \mathrm{E}+00$ & -0.92 & $4.05 E-4$ \\
\hline
\end{tabular}




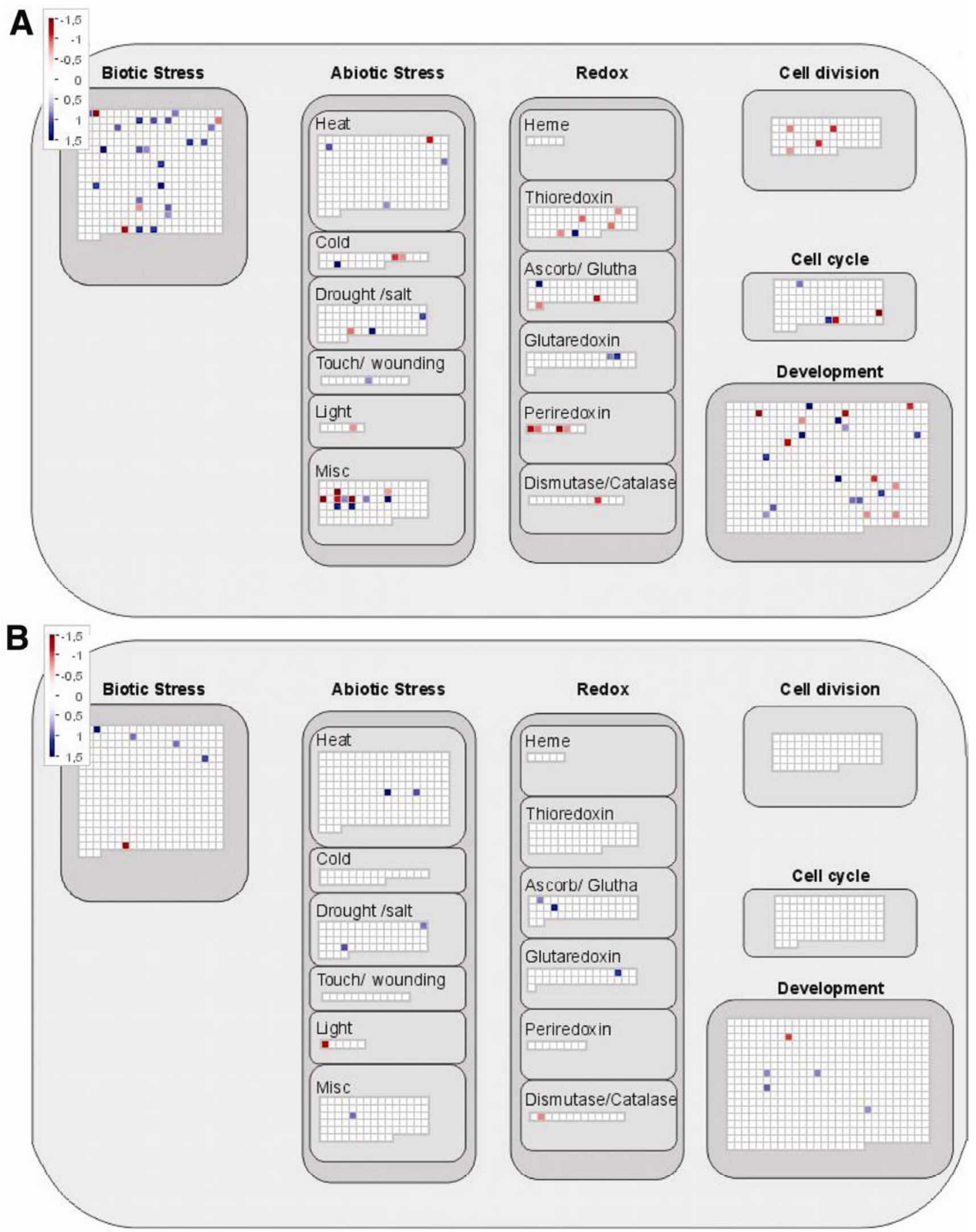

Fig. 5. Bradyrhizobium sp. strain ORS278 counterbalances the impact of Pseudomonas syringae pv. tomato pathogenesis on host metabolism. A, The MapMan cellular response overview display, created using the 707 Pseudomonas syringae pv. tomato-regulated genes identified from the P. syringae pv. tomato DC3000-challenged plants versus control comparison. B, The MapMan cellular response overview display created using the 151 induced systemic resistance (ISR)-regulated genes identified from the ORS278-colonized and $P$. syringae pv. tomato DC3000-challenged plants versus control comparison. C, The MapMan metabolism overview display created using the 707 Pseudomonas syringae pv. tomato-regulated genes identified from the $P$. syringae pv. tomato DC3000-challenged plants versus control comparison. D, The MapMan metabolism overview display created using the 151 ISR-regulated genes identified from the ORS278-colonized and P. syringae pv. tomato DC3000-challenged plants versus control comparison. The fold change is displayed as illustrated in the fold change color bar in the upper left of each panel (red is repressed, blue is induced). 

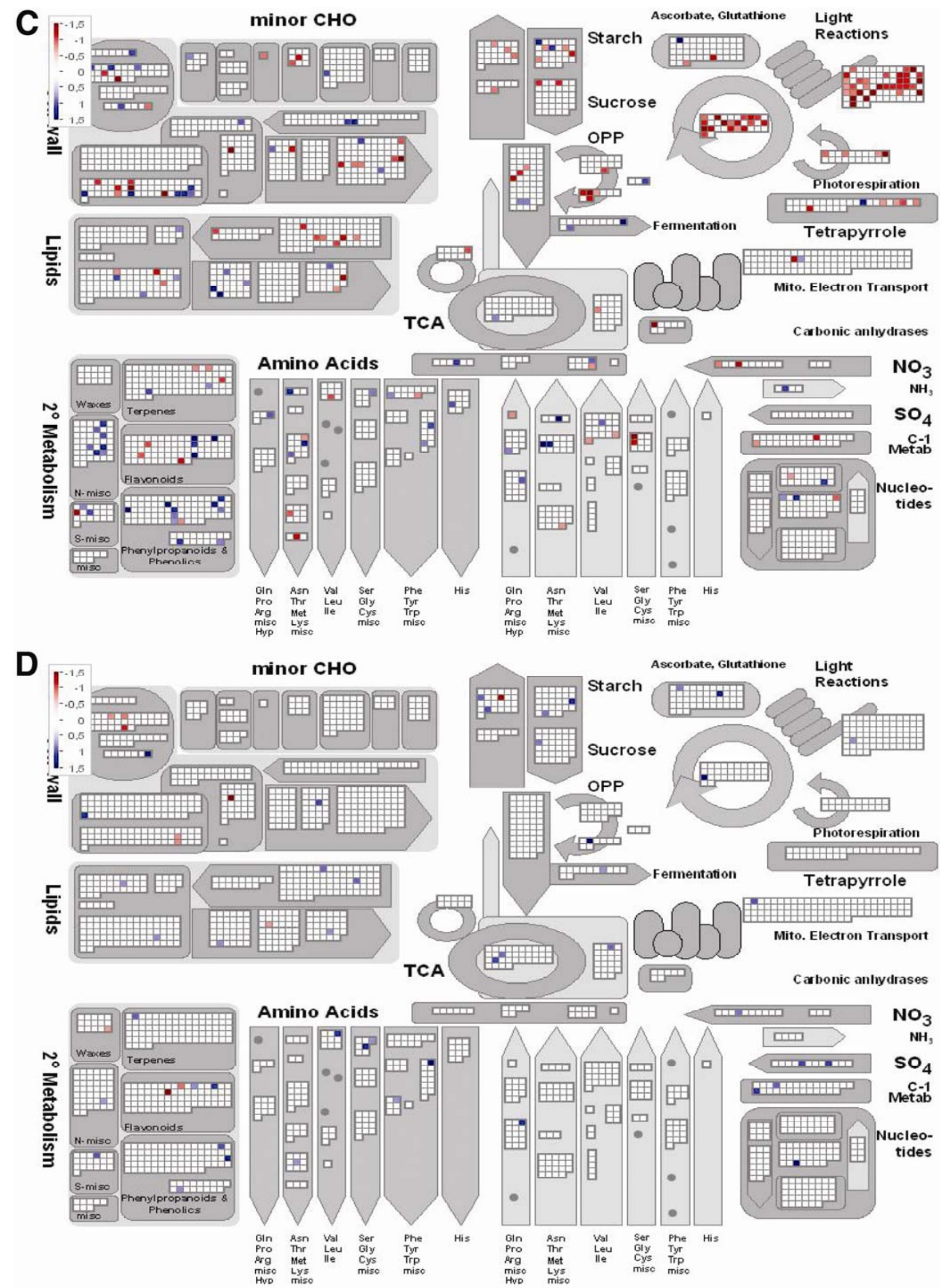

Fig. 5. Continued from preceding page. 
primers are shown in Figure 6B. The expression of PDF1.1, $P D F 1.4$, and $P D F 1.5$ genes was not changed in any condition tested. By contrast, PDF1.2b, PDF1.2c, and PDF1.3 were upregulated upon inoculation with Bradyrhizobium sp. strain ORS278 in the absence of pathogen challenge. PDF 1.2a exhibited a typical primed ISR-specific gene expression pattern. According to these results, we assume that the pattern of expression revealed by CATMA experiments reflected the sum of $P D F 1.2$ and PDF 1.3 expressions.

\section{DISCUSSION}

In the present study, a global analysis of leaf transcript modifications associated with the Arabidopsis-Bradyrhizobium sp. strain ORS278 interaction in relation to responses to a leaf pathogen was performed using CATMA DNA chips (Crowe et al. 2003; Hilson et al. 2004).

Since we were interested in identifying components of the signaling cascades leading to ISR onset and additional targets of these cascades, it appeared to us mostly appropriate to investigate in parallel changes in transcription induced by $\mathrm{Bra}$ dyrhizobium sp. strain ORS278 in Arabidopsis and those induced by Bradyrhizobium sp. strain ORS278 in P. syringae pv. tomato DC3000-challenged Arabidopsis. Actually previous studies performed either with plant growth-promoting fungi or PGPR tend to demonstrate that priming is a common feature of the resistance responses induced by beneficial microorganisms (Conrath et al. 2006). For all these reasons, we chose to compare four classes of samples: control leaves, ORS278-protected plant leaves, $P$. syringae pv. tomato DC3000-challenged plant

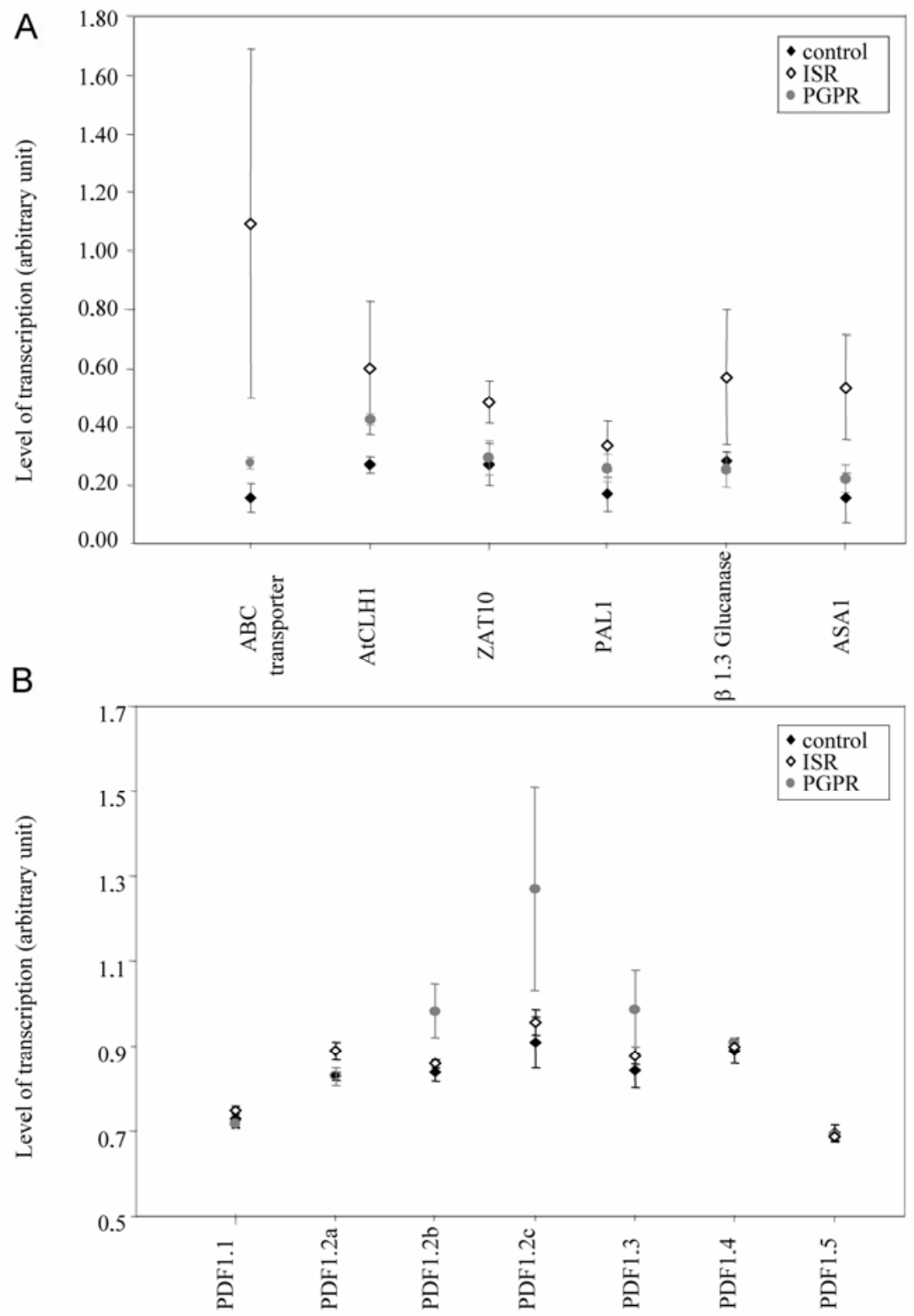

Fig. 6. Expression pattern of the ABC transporter [AT1G59870], AtCLH1, ZAT10, PAL1, $\beta$-1,3-glucanase [AT4G16260], ASA1, and PDF1s genes in plants expressing induced systemic resistance (ISR) mediated by Bradyrhizobium sp. strain ORS278. The gene expression levels were quantified by real-time reverse transcriptase-polymerase chain reaction. Three treatments are compared: i) control plants in which leaves were infiltrated with sterile $\mathrm{MgSO}_{4}$ solution, ii) plant growth-promoting rhizobacteria plants cocultivated with Bradyrhizobium sp. strain ORS278 and infiltrated with sterile $\mathrm{MgSO}_{4}$ solution, and iii) ISR plants cocultivated with Bradyrhizobium sp. strain ORS278 and infiltrated with a $2 \times 10^{5} \mathrm{CFU} / \mathrm{ml}$ suspension of Pseudomonas syringae pv. tomato DC3000. Plants were 4 weeks old, and all samples were collected $24 \mathrm{~h}$ after infection. A, ABC transporter [AT1G59870], AtCLH1, ZAT10, PAL1, $\beta-1,3-$ glucanase [AT4G16260], and $A S A 1$ expression level in shoots of control and treated plants is expressed relatively to the constitutive AtACT2 gene expression level. B, PDF1 subfamily gene expression level in shoots of control and treated plants. Average \pm standard error from three independent experiments (biological variability) are given. 
leaves, and protected-challenged plant leaves. Five cross-hybridizations were performed: ORS278-protected plants versus control leaves, $P$. syringae pv. tomato DC3000-challenged plants versus control leaves and protected-challenged plants versus, respectively, control leaves, ORS278-protected leaves, and $P$. syringae pv. tomato DC3000-challenged leaves.

Since metabolic changes are in part correlated to transcriptional changes, we extracted soluble metabolites and performed a metabolite fingerprinting analysis to determine if it was or was not convenient to pool our samples before CATMA hybridization. This metabolome fingerprinting showed that biological replications were highly homogeneous and allowed us to pool the nine biological samples corresponding to each treatment.

\section{Bradyrhizobium sp. strain ORS278 down-regulates} host gene expression.

The CATMA data study (Fig. 4) showed that: i) 203 of the 22,089 genes tested displayed a downregulation of their expression in response to colonization by Bradyrhizobium sp. strain ORS278, and ii) none of them showed an upregulation, except for the PDF1.2 genes subfamily. The shift in the expression of 203 genes detected in leaves indicates that the presence of Bradyrhizobium sp. strain ORS278 on Arabidopsis roots could be perceived systemically in leaves. It is noteworthy that the expression of almost all these genes was down-regulated. This trend is consistent with a previous large-scale transcriptome analysis of Arabidopsis-P. fluorescens WCS417r interaction, which showed that the majority of 97 genes responding to ISR-inducing rhizobacteria were actually down-regulated (Verhagen et al. 2004). Contrary to our study, in the case of Pseudomonas fluorescens WCS417r-mediated ISR, gene expression levels were recorded in the roots and not in the leaves, and the microarrays used represented only a third of the Arabidopsis genome. Transcriptome analyses of Arabidopsis colonized by Pseudomonas thivervalensis MLG45 or Pseudomonas fluorescens FPT9601-T5, respectively, showed equivalent number of genes up- and downregulated upon PGPR inoculation (Cartieaux et al. 2003; Wang et al. 2005). The apparent discrepancy between the present data and those previously obtained in

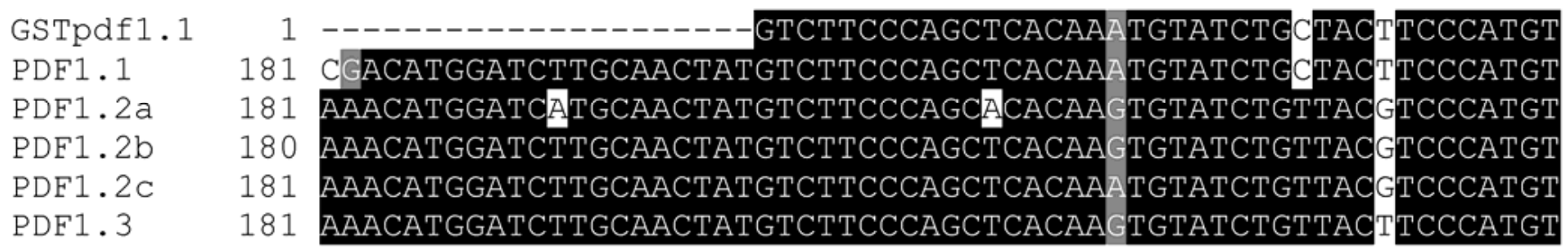

GSTpdf1.1
PDF1.1
PDF1.2a
PDF1.2b
PDF1.2C
PDF1.3

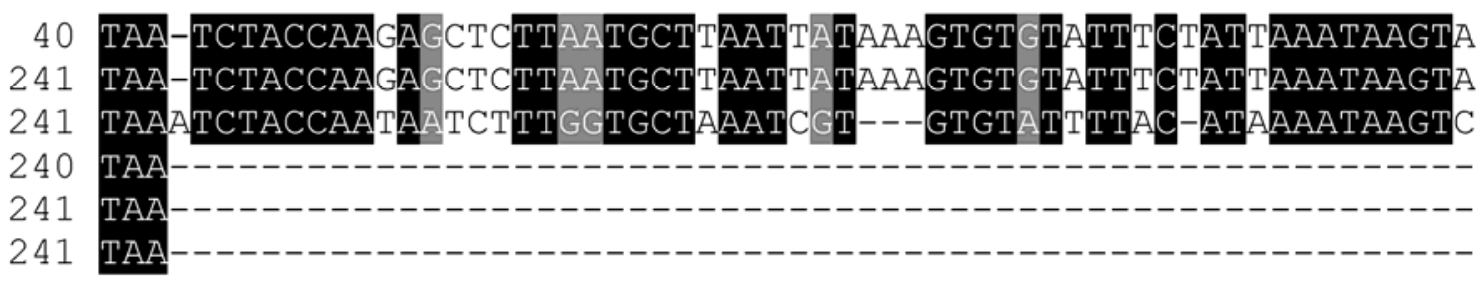
GSTpdf 1.1
PDF1.1
PDF1.2a
PDF1.2b
$\mathrm{PDF} 1.2 \mathrm{C}$
PDF1.3

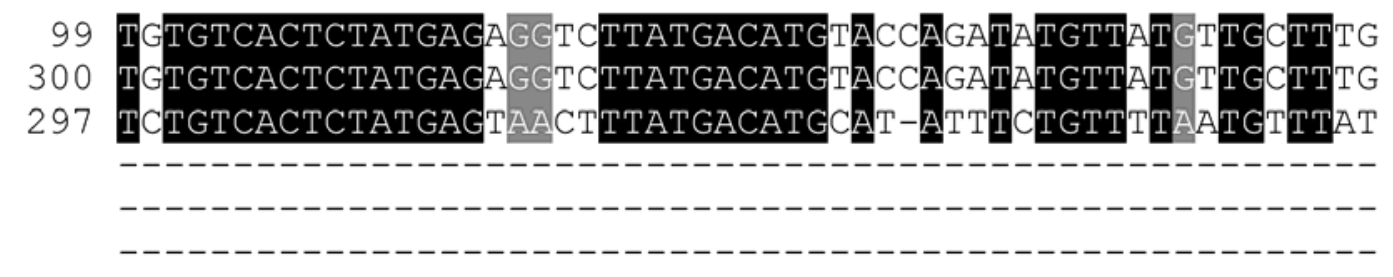

Fig. 7. GSTpdf1.1, the PDF1.1 gene-specific sequence tag spotted on CATMA microarray. The GSTpdf1.1 sequence shared a 40-bp consensus with the sequences of four members of the PDF1 subfamily, PDF1.2a, PDF1.2b, PDF1.2c, and PDF1.3. Conserved amino acids are highlighted.

Table 2. Gene specific primer sets for real-time reverse transcriptase-polymerase chain reaction amplification

\begin{tabular}{|c|c|c|c|c|}
\hline AGI Code & Name & Forward primer & Reverse primer & Product size (bp) \\
\hline At2g37040 & PAL1 & ACCAAAAACGGTGTCGCACTT & GCGGAGTGTGGCAATGTGTG & 101 \\
\hline At4g16260 & & AGTGGAGAATCAGTAGGTGTATG & GGCTTGGTTTGGATCGTAGAGT & 126 \\
\hline Atlg19670 & AtCHL1 & AAGTGGAAGTGGACGATGC & CCGAAGTTGGTAGGTGAGC & 75 \\
\hline At1g59870 & PEN3 & TCGTGTACCAAGGACCGAGAGA & CTTTCTTGGAAGTAACCTCTTGCAG & 114 \\
\hline At1g27730 & ZAT10 & GTGTCCAACTCCGAAGGTGC & TTGACCATCGAGAATTCAGGG & 101 \\
\hline At5g05730 & ASA1 & GCGTTGGTCGTTATAGCGTTG & TGGGATCTCCATTGGATCTTCG & 134 \\
\hline AT1g75830 & PDF1,1 & GCTAAGTCTGCTACCATCGTTAC & TGCTTCCACCACCATCGG & 84 \\
\hline AT5G44420 & PDF1,2a & CTTGTTCTCTTTGCTGCTTTCGAC & ATGCATTACTGTTTCCGCAAACC & 106 \\
\hline AT2G26020 & PDF1,2b & TTCСАТСАТСАССТTТАТСТАCG & CCGCAAACTCCTGACCAAGTA & 120 \\
\hline AT5G44430 & PDF1,2c & CTGCTACCATCATCACCTTCC & CCGCAAACGCCTGACCATGTC & 126 \\
\hline AT2G26010 & PDF1,3 & GCCATCATCACTTTCCTCTTC & TTCTGTGCTTCCACCATTATC & 77 \\
\hline AT1G19610 & PDF1,4 & GATGATGGCGGTGGAAGGAAG & CGGGAACTGAGCGTGACAAG & 139 \\
\hline AT1G55010 & PDF1,5 & TAACAATGATAGAGGAAATGATGG & TTAGCAAGAGAAGAAACAGAAAC & 82 \\
\hline AT3G18780 & $\mathrm{ACT} 2$ & TCССТCAGCACATTCCAGCAGAT & AACGATTCCTGGACCTGCCTCATC & 69 \\
\hline
\end{tabular}


the MLG45-Arabidopsis interaction is most likely due to the fact that the previous study was performed in the Arabidopsis accession Ws-0, which is known to be blocked in its ability to express JA- and ET-dependent ISR, such as that triggered by $P$. fluorescens WCS417r (Ton et al. 1999, 2001). By inference, $P$. thivervalensis MLG45 is likely to induce in Arabidopsis a signaling pathway different from those induced by $P$. fluorescens WCS417r or Bradyrhizobium sp. strain ORS278. Likewise, Pseudomonas fluorescens FPT9601-T5-mediated protection might be achieved through alternative pathways, since this ability has been partly linked to production of antibiotics, siderophores, and proteases (Wang et al. 2005).

A MapMan overview metabolism map revealed that changes in expression induced by Bradyrhizobium sp. strain ORS278 colonization were completely different from the pathogen signature (Figs. 4 and 5A and C). Challenging Arabidopsis with $P$. syringae pv. tomato DC3000, as previously pointed out by Thilmony and coworkers (2006), leads to a significant repression of photosynthetic genes, coupled with an induction of defense-related genes (Fig. 5A). Conversely, colonization of Arabidopsis roots by Bradyrhizobium sp. strain ORS278 is illustrated by a weak impact on photosynthetic genes and by the repression of some genes involved in response to biotic and abiotic stresses, including two leucine-rich repeat proteinrelated (AT2G26380 and AT4G04220), one MLO-like protein (AT4G02600), two heat shock proteins (AT2G29970 and AT4G16660), and two dehydratation-responsive proteins (AT2G34300 and AT1G 29470) (Fig. 4). Since ORS278 had no significant impact on shoot growth in the culture conditions used for our transcriptome analysis, these transcript level changes cannot be explained by an indirect effect of the PGPR strain via physiological changes. Alternatively, an appealing hypothesis would be that Bradyrhizobium sp. strain ORS 278 might counteract some parts of defense signaling pathways of the host plant to make its colonization possible.

\section{Role of oxylipins in ISR.}

Although the leaves clearly responded to root colonization by Bradyrhizobium sp. strain ORS278, no major changes in the expression of defense genes have been associated with ORS278-mediated ISR, probably because this would be a metabolic burden for the host (Van Hulten et al. 2006). This observation is consistent with the study of Verhagen and coworkers (2004), which confirmed that ISR did not seem to be associated with detectable increases in expression of genes tested so far. On the other hand, our analysis and theirs underscored a set of genes whose expression was modified only after $P$. syringae pv. tomato DC3000 challenge in ISR-expressing plants and so-called primed ISR genes. Considering that genes whose expression was modified either in ISR-expressing plants or pathogen-challenging plants should not be taken into account, we found 64 primed ISR-specific genes in ORS278colonized plants after pathogen attack as compared with the number found in control plants (Table 1).The expression of one fourth of these ISR-specific genes has been found to be modulated by JA in other studies (digital Northern performed with Genevestigator; Zimmermann et al. 2004). We focused on this subset of genes because JA has been well described as a major regulator of plant signaling involved in response to either necrotrophic pathogens, wounding, or both (Schilmiller and Howe 2005) and a key component for ISR onset (Pieterse et al. 1998). Actually, mutant analysis showed that WCS417rmediated ISR requires an intact response to JA and ET and that this requirement is not related to any increase in the production of these hormones (Pieterse et al. 1998, 2000). Among those JA- and ET-responsive ISR-primed genes, PDF1.2a, a thaumatin-like gene, seems of particular interest, as it is the only
ISR-primed gene shared between Pseudomonas fluorescens WCS417r- and Bradyrhizobium sp. strain ORS278-mediated ISR (Verhagen et al. 2004; this study).

Cross-talk between ET and JA signaling pathways determines the activation of a set of defense responses against pathogens and herbivores (Glazebrook 2001). A recent study identified ERF1 as one of the molecular targets that could underlie this cross-talk (Lorenzo et al. 2003). The expression of this transcription factor could be activated synergistically by both hormones, and its ectopic expression led to the induction of the expression of pathogen-response genes. It is notable that three genes currently established to fit in the ISR-specific gene category (Verhagen et al. 2004; this study), $A S A 1$, a $\beta$-1,3-glucanase (AT4G16260), and PDF1.2a, were induced synergistically by ET and JA and were expressed constitutively in Col-0:35S:ERF1 plants (Lorenzo et al. 2003). By contrast, the same study showed that ASAl was not induced by either JA or ET alone, $\beta$-1,3-glucanase was only weakly induced by ET and not by JA, and PDF1.2a was induced by JA but not by ET. According to these data, the former hypothesis of a signal transduction leading to ISR in which JA and ET responses are engaged successively (Pieterse et al. 1998) should be reexamined and presumably completed with a pathway in which JA and ET act synergistically (Lorenzo et al. 2003).

Although attention has focused mainly on JA as a signal, the possibility that the JA precursor 12-oxo-phytodienoic acid (OPDA) could itself be biologically active has been proposed (Mueller 1997). The isolation of an opr3 Arabidopsis mutant that could not produce JA but did accumulate OPDA demonstrated that OPDA was a potent regulator of defense response genes (Stintzi et al. 2001). Recently, using DNA microarrays covering $80 \%$ of the Arabidopsis genome, Taki and coworkers (2005) identified a group of genes that responded to OPDA but not to JA. A large percentage of OPDA-specific response genes $(45 \%)$ were involved in stress responses such as wounding, salt stress, or heat shock. These included many signal transduction components and transcription factors, for instance, WRKY53 and ZAT10, which were identified as ISR-specific genes in our study. The genes coding for a putative cytochrome P450 (AT5G45340) and a mitochondrial carrier (AT2G22500) protein, which have also been shown to be OPDA-specific response genes (Taki et al. 2005), appeared to be ISR-specific genes in our study (Table 1). Those four genes have never been identified as PGPR-induced nor ISR-specific in previous transcriptome large-scale analyses. Finally, $25 \%$ of the putative JA-responsive genes that we identified among ISR-specific genes appeared to actually be OPDA-responsive. To our knowledge, these figures constitute the first report of OPDAdriven expression level changes in ISR-expressing plants. This evidence suggests that OPDA may act in parallel with JA for ISR settlement. In order to assess this hypothesis, it would be helpful to determine if ISR can still be achieved, at least partly, in an opr3 mutant of Arabidopsis.

\section{Bradyrhizobium sp. strain ORS278 counterbalances the impact of $P$. syringae pv. tomato pathogenesis on host metabolism.}

The MapMan overview metabolism map showing the $707 P$. syringae pv. tomato-regulated genes identified in our study revealed a repression of photosynthetic genes involved either in light reactions or the Calvin-Benson-Bassham cycle and an induction of genes related to biotic stress (Fig. 5C). The appropriation of host resources (including sugars produced by photosynthesis) by the pathogen might have led to a concomitant regulation of photosynthesis and defense response genes. The induction of pathogenesis-related (PR) gene expression by 
either exogenous sugars or ectopic expression of invertase and the characterization of the Arabidopsis mutant hys1/cpr5, which is not only hypersensitive to sugar but also constitutively expresses PR genes, form a network of evidence for the existence of a link between sugar and stress signaling (Herbers et al. 1995; Thibaud et al. 2004; Yoshida et al. 2002). It has been well-described that pathogens locally activate invertases in correlation with increased soluble sugar levels at the infection site (Chou et al. 2000). According to these data, a common sugar-sensing mechanism acting to repress photosynthetic gene expression and stimulate defense protein genes has been proposed (Sheen et al. 1999). It was actually assumed that the expression of defense-related genes was dependent on glycolysis, while sucrose exerted its control on the expression of photosynthesis genes through a glucose sensor pathway (Xiao et al. 2000).

Among the photosynthetic genes whose expression has been typically described to be mediated by a hexokinase-dependent pathway, CAB1 (chlorophyll a/b-binding protein, AT3G54890) and $r b c S$ (rubisco small subunit 3, AT5G38410) were repressed by $P$. syringae pv. tomato DC3000 (Fig. 5C; Thilmony et al. 2006; Xiao et al. 2000). Amazingly, their expression levels recovered control values when plants were 'protected' by Bradyrhizobium sp. strain ORS278 previous to the pathogen attack (Fig. 5D). It should be remembered here that samples used for CATMA hybridizations were collected $24 \mathrm{~h}$ after infection, which means prior to a detectable reduction of Pseudomonas syringae population in ORS278-treated plants. As a consequence, we assume that the changes observed may be directly linked to the regulatory effects of Bradyrhizobium sp. strain ORS278 on gene expression rather than to indirect effects of ORS278-induced ISR on pathogen population density.

A parallel pattern was observed for disease resistance proteins (AT1G52900, AT1G66090, AT1G72940, and AT5G22690) and for genes related to secondary metabolism, such as glutathione $S$-transferase (AT5G17220, AT1G74590, AT1G78380, or AT1G69930), whose expression levels were up-regulated by $P$. syringae pv. tomato DC3000 but resumed control levels under ISR conditions (Fig. 5A and B; Lloyd and Zakhleniuk 2004). Actually, a global analysis of the microarray data showed that, among the 707 genes exhibiting transcription changes following pathogen attack, 684 genes recovered a level of expression similar to that in control plants when the plants are protected by Bradyrhizobium sp. strain ORS 278 colonization prior to pathogen challenge. Overall, the MapMan metabolism map demonstrated that Bradyrhizobium sp. strain ORS278 counteracted most of the transcription changes elicited by $P$. syringae pv. tomato DC3000 (Fig. 5). The fact that Bradyrhizobium sp. strain ORS278 switches off $P$. syringae pv. tomato DC3000 impact on the host transcriptome is almost certainly the mark of a successful protection. This protection could operate through priming of defense-related genes described above. Among ISR-specific genes identified in this study, a prolinerich cell wall protein (AT4G38770) seems to be a good candidate for a further reverse genetic approach, since it was downregulated by $P$. syringae pv. tomato DC3000 and was up-regulated in ISR-expressing plants after pathogen challenge (Table 1). This peculiar pattern of expression and the property of this proline-rich protein to be rapidly insolubilized within the cell wall in response to pathogen infection strongly indicate an active role in plant defense reactions, probably through cellwall thickening (Fowler et al. 1999).

\section{Conclusion.}

How PGPR trigger ISR remains a matter of inquiry. Geneprofiling experiments have provided a valuable tool for the characterization of a pseudomonad colonization phenotype
(Cartieaux et al. 2003; Verhagen et al. 2004; Wang et al. 2005). The original approach of Verhagen and coworkers (2004) (analysis of ISR-expressing plants challenged by pathogens) revealed the dominant role of priming for Pseudomonas fluorescens WCS417r-mediated ISR. Our study based on a Bradyrhizobium sp. strain ORS278-mediated resistance has confirmed that priming is likely to be a common feature of ISR. Furthermore, for the first time, we provide evidence that OPDA may be an additional actor in the signaling cascade leading to ISR. In addition, analyzing the microarray data with the Mapman analysis toolbox allowed us to obtain an overview of the effect of Bradyrhizobium sp. strain ORS278 on transcription changes induced by the pathogen. One of the most remarkable pattern thus revealed was the ability of Bradyrhizobium sp. strain ORS278 to counterbalance the impact of $P$. syringae pv. tomato on the host metabolism.

\section{MATERIALS AND METHODS}

\section{Plant growth conditions.}

Seeds of Arabidopsis thaliana ecotype Columbia (Col-0) were surface-sterilized by immersion in $3 \%$ (wt/vol) calcium hypochlorite and $0.01 \%$ ( vol/vol) Tween 20 filtrate and were washed with sterile distilled water. The seeds were sown on a $0.8 \%(\mathrm{wt} / \mathrm{vol})$ standard agar mineral medium containing 0.5 $\mathrm{mM} \mathrm{CaSO}_{4}, 2 \mathrm{mM} \mathrm{KNO} 3,1 \mathrm{mM} \mathrm{KH}{ }_{2} \mathrm{PO}_{4}, 0.5 \mathrm{mM} \mathrm{MgCl}_{2}, 50$ $\mu \mathrm{M} \mathrm{H}_{3} \mathrm{BO}_{3}, 15 \mu \mathrm{M} \mathrm{MnCl}_{2}, 50 \mu \mathrm{M} \mathrm{Na}_{2} \mathrm{Fe}$-EDTA, $1 \mu \mathrm{M} \mathrm{ZnCl}{ }_{2}$, $1 \mu \mathrm{M} \mathrm{CuCl} 2,0.03 \mu \mathrm{M}\left(\mathrm{NH}_{4}\right)_{6} \mathrm{Mo}_{7} \mathrm{O}_{24}$, and $2.5 \mathrm{mM}$ morpholineethanesulfonic acid (Mantelin et al. 2006). The seeds were incubated at $4^{\circ} \mathrm{C}$ for $48 \mathrm{~h}$ as dormant releasing, and then, the plates were placed in a growth chamber with $60 \%$ relative humidity at a $22^{\circ} \mathrm{C}$ light and $18^{\circ} \mathrm{C}$ dark thermoperiod with a photoperiod of $12 \mathrm{~h}$ of light and $12 \mathrm{~h}$ of dark. After a week, plants were replanted in potting soil and were maintained in the growth chamber with a photoperiod of $8 \mathrm{~h}$ of light and $16 \mathrm{~h}$ of dark. Plants were watered with tap water twice a week.

\section{Bacteria growth conditions.}

Bradyrhizobium sp. strain ORS278 was grown aerobically in yeast extract-mannitol medium (Vincent 1970) on a rotary shaker $(120 \mathrm{rpm})$, with 5 days of incubation at $37^{\circ} \mathrm{C}$. Bacterial cells collected by centrifugation were resuspended in sterile liquid mineral medium (Mantelin et al. 2006) to inoculate the soil to which plants were transferred to soil at a final density of $10^{7} \mathrm{CFU} / \mathrm{g}$.

Pseudomonas syringae pv. tomato DC3000 (Whalen et al. 1991) was cultivated in King's B medium supplemented with rifampicin $(50 \mu \mathrm{g} / \mathrm{ml})$ at $28^{\circ} \mathrm{C}$ for $24 \mathrm{~h}$. Cells collected by centrifugation were resuspended in $10 \mathrm{mM} \mathrm{MgSO}_{4}$ to a final density of $2.5 \times 10^{5} \mathrm{CFU} / \mathrm{ml}$ for manual infiltration of Arabidopsis.

\section{Bioassay of ISR by Bradyrhizobium sp. strain ORS278.}

One-week-old seedlings of Arabidopsis plants were transplanted into autoclaved potting soil inoculated with Bradyrhizobium sp. strain ORS278 in order to obtain a final concentration of bacteria of $10^{7} \mathrm{CFU} / \mathrm{g}$. The control soil was not bacterized. To evaluate induced resistance, plants were challenge-inoculated three weeks after potting by manual infiltration of Pseudomonas syringae pv. tomato at a concentration of $2.5 \times 10^{5}$ $\mathrm{CFU} / \mathrm{ml}$, and bacterial growth measurements were carried out as described by Lummerzheim and coworkers (1993).

\section{Steady-state metabolite fingerprinting analysis using GC-EI-TOF-MS.}

Soluble metabolites were extracted and analyzed essentially as described by Desbrosses and coworkers (2005). GC-EITOF-MS applied to the metabolite profiling of methoxyami- 
nated and trimethylsilylated metabolite fractions was as first described (Wagner et al. 2003) and as detailed by Erban and associates (2007). In short, homogenization was performed in liquid nitrogen using $60 \pm 5 \mathrm{mg}$ of leaf material. Extraction was $300 \mu \mathrm{l}$ of precooled $\left(-20^{\circ} \mathrm{C}\right)$ absolute methanol. To each sample, $30 \mu \mathrm{l}$ of a methylnonadecanoate stock solution ( $2 \mathrm{mg}$ $\mathrm{ml}^{-1}$ methanol) (Sigma-Aldrich, Steinheim, Germany) and 30 $\mu \mathrm{l}$ of a ribitol stock solution $\left(0.2 \mathrm{mg} \mathrm{ml}^{-1}\right.$ methanol) (SigmaAldrich) were added. After shaking at $70^{\circ} \mathrm{C}$ for $15 \mathrm{~min}, 200 \mu \mathrm{l}$ of chloroform was added to the samples, which were further shaken at $37^{\circ} \mathrm{C}$ for an additional $5 \mathrm{~min}$. Then, $400 \mu \mathrm{l}$ of $\mathrm{H}_{2} \mathrm{O}$ was added. Centrifugation was performed after vortexing at $16,000 \times g$ for $5 \mathrm{~min}$ at room temperature. Aliquots of the upper polar phase $(80 \mu \mathrm{l})$ were dried by vacuum centrifugation (Concentrator 5301, Eppendorf, Hamburg, Germany). Chemical derivatization (Fiehn et al. 2000; Roessner et al. 2000) and GC-TOF-MS metabolite profiling analysis (Erban et al. 2007; Wagner et al. 2003) was performed essentially as described previously. Retention time calibration was performed using the Kovàts indices (Kovàts 1958), which were calculated from standard additions to each chromatogram of a mixture of $\mathrm{C} 12$, C15, C19, C22, C32, C36 n-alkanes. Metabolite fingerprinting was performed after mass spectral deconvolution (ChromaTOF software version 1.00, Pegasus driver 1.61, LECO, St. Joseph, MI, U.S.A.). Peak height of each deconvoluted mass fragment representing an arbitrary mass spectral ion current was recorded and normalized using the amount of the sample fresh weight and the ion current representing the ribitol analyte for internal standardization of volume and amount variations.

\section{Numerical and statistical analysis.}

The resulting data set represents the normalized response of all deconvoluted mass fragments $\left(\mathrm{N}_{\mathrm{i}}\right)$, which were observed in each of the biological conditions and respective replications. A $\log$-transformed data set based on response ratios, $\log _{10}\left(\mathrm{R}_{\mathrm{i}}\right)$, was used as described earlier (Desbrosses et al. 2005). In this study, the mean normalized response value of each mass fragment was used to calculate response ratios. Missing values were substituted using replicate group averages prior to HCA, which was performed according to Desbrosses and associates (2005). ANOVA, $P<0.05$, was used to remove all mass fragments from further analysis, which do not contribute to the differentiation of sample or which were caused by biological treatment, for example, those mass fragments that represent invariant laboratory contaminations or added internal standard compounds or metabolites that remained nonresponsive to the experimental regime. Alternatively, all mass fragments representing internal standards or laboratory contaminations were removed manually. ICA was performed after ANOVA or after manual removal of laboratory contaminations and internal standards according to Scholz and coworkers (2004, 2005).

\section{RNA extraction and microarrays analysis.}

The microarray analysis was performed using CATMA arrays containing 24,576 GST corresponding to 22,089 genes, including 21,612 AGI-predicted genes and 477 Eugene-predicted genes from A. thaliana (Crowe et al. 2003; Hilson et al. 2003). The GST amplicons were purified on multiscreen plates (Millipore, Bedford, MA, U.S.A.) and were resuspended in Tris-EDTA-dimethyl sulfoxide at $100 \mathrm{ng} \mu \mathrm{l}^{-1}$. The purified probes were transferred to 1,536-well plates with a Genesis workstation (TECAN, Männedorf, Switzerland) and were spotted on UltraGAPS slides (Corning, NY, U.S.A.) using a Microgrid II (Genomic Solutions, Huntingdon, U.K.). The current CATMA version printed at the Unité de Recherche en Génomique Végétale (URGV, Evry, France) consists of three metablocks, each composed of 64 blocks of 144 spots. A block is a set of spots printed with the same print-tip. In these arrays, a print-tip is used three times to print a block in each metablock.

Five comparisons were analyzed in this timecourse analysis. In the first three comparisons, each array was hybridized at the same time with cRNA from i) ORS278-protected plants, ii) $P$. syringae pv. tomato DC3000-challenged plants, and iii) ORS278/P. syringae pv. tomato DC3000 treated plants versus control leaves that were labeled with $\mathrm{Cy} 3$ and $\mathrm{Cy} 5$ fluorescent dyes, respectively. The fourth and fifth comparisons correspond to hybridization with cRNA from protected-challenged plants versus cRNA from ORS278-protected plants or $P$. syringae pv. tomato DC3000-challenged plants, respectively. Plants were cocultivated three weeks with Bradyrhizobium sp. strain ORS278 before challenge by $P$. syringae pv. tomato DC3000, and samples were collected $24 \mathrm{~h}$ after infection by the pathogen. This timepoint was chosen in regard to a previous study that has demonstrated that JA-responsive genes displayed a maximum of expression in ISR-expressing plants one day after infection by the pathogen (Van Wees et al. 1999). It is worthwhile to mention that $24 \mathrm{~h}$ postinfection neither obvious disease symptoms on infected leaves of ORS278-protected plants nor any significant difference in pathogen population size between control and ISR-expressing plants was found (data not shown). Material for each RNA extraction consists of nine independent treated leaves harvested $24 \mathrm{~h}$ after pathogen or $\mathrm{MgSO}_{4}$ challenge from three plants (three leaves per plant). For each comparison, RNAs from three independent biological repetitions were pooled as recommended by Peng and coworkers (2003) in order to take into account the biological variation while minimizing the total cost. In addition, to avoid dye bias and gene-specific dye bias, a dye-swap experiment was carried out: the cRNAs labeled with $\mathrm{Cy} 3$ in the first array was labeled with Cy5 in the second (Martin-Magniette et al. 2005). Therefore, two arrays were used for each comparison assay.

RNA was extracted using the SV total RNA isolation system (Promega, Charbonnières, France). cRNAs were produced from $2 \mu \mathrm{g}$ of total RNA from each pool with the Message Amp aRNA kit (Ambion, Austin, TX, U.S.A.). Then, $5 \mu \mathrm{g}$ of cRNAs were reverse-transcribed in the presence of $200 \mathrm{U}$ SuperScript II (Invitrogen), cy3-dUTP, and cy5-dUTP (NEN, Boston) for each slide, according to Puskas and coworkers (2002). Samples were combined, purified, and concentrated with YM30 Microcon columns (Millipore). Slides were prehybridized for $1 \mathrm{~h}$ and were hybridized overnight at $42^{\circ} \mathrm{C}$ in $25 \%$ formamide. Slides were washed in $2 \times \mathrm{SSC}(1 \times \mathrm{SSC}$ is $0.15 \mathrm{M} \mathrm{NaCl}$ plus $0.015 \mathrm{M}$ sodium citrate) $+0.1 \%$ sodium dodecyl sulphate for 4 min, $1 \times$ SSC for $4 \mathrm{~min}, 0.2 \times \mathrm{SSC}$ for $4 \mathrm{~min}, 0.05 \times \mathrm{SSC}$ for 1 min and were dried by centrifugation. A total of 20 hybridizations (10 dye-swaps) were carried out. The arrays were scanned on a GenePix 4000A scanner (Axon Instruments, Foster City, CA, U.S.A.), and images were analyzed using Genepix pro 3.0 (Axon Instruments).

Statistical analysis of microarray data experiments was designed with the statistics team of the URGV. The statistical analysis was based on one dye-swap (i.e., two arrays, each containing 24,576 GST and 384 controls). The controls were used for assessing the quality of the hybridizations but were not included in the data presented. For each array, the raw data comprised the logarithm of median feature pixel intensity at wavelengths $635 \mathrm{~nm}$ (red) and $532 \mathrm{~nm}$ (green). No background was subtracted. In the following description, log ratio refers to the differential expression between two conditions. It is either $\log _{2}$ (red/green) or $\log _{2}$ (green/red) according to the experiment design. An array-by-array normalization was performed to remove systematic biases. First, we excluded spots that were considered badly formed features. We then performed a global intensity-dependent normalization using the LOESS procedure 
to correct the dye bias. Finally, for each block, the log-ratio median calculated over the values for the entire block was subtracted from each individual log-ratio value to correct print-tip effects on each metablock. To determine differentially expressed genes, we performed a paired $t$ test on the log ratios, assuming that the variance of the log-ratios is the same for all genes. Spots displaying extremes of variance (too small or too large) were excluded. The raw $P$ values were adjusted by the Bonferroni method, which controls the family wise error rate (FWER). We considered as being differentially expressed the genes with a FWER lower than 5\% (Lurin et al. 2004). The data were deposited in Array express according to the MIAME standards (accession number E-MEXP-386).

\section{Reverse transcriptase (RT)-PCR.}

Total RNA was isolated as described above. Total RNA used for RT-PCR confirmation were obtained from plants that were grown independently from those used to isolate RNA for microarray analysis. In addition, three independent biological assays were carried out from plant culture to RNA extraction. RNA quality was assayed by UV spectrophotometry. First-strand cDNA was synthesized from $500 \mathrm{ng}$ of total RNA, using the SuperScript II reverse transcriptase (Invitrogen), according to manufacturer recommendations.

Real-time PCR assays were performed using the Mx3000P quantitative PCR system (Stratagene, La Jolla, CA, U.S.A.) with the qPCR mastermix for Sybr green I kit (Eurogentec, Seraing, Belgium), according to the manufacturer's recommendations. Each reaction was performed on $0.1 \mu \mathrm{l}$ of template first cDNA strands, in a final reaction volume of $20 \mu \mathrm{l}$. Specific primer sets were designed for the $P A L 1$, At4g16260, AtCLH1, PEN3, ZAT10, ASA1, and PDFs genes (Table 2). DNA amplification was performed with the following thermal cycling profile: initial denaturation at $94^{\circ} \mathrm{C}$ for $10 \mathrm{~min}, 40 \mathrm{cy}$ cles of amplification (denaturation at $94^{\circ} \mathrm{C}$ for $30 \mathrm{~s}$, annealing at $60^{\circ} \mathrm{C}$ for $30 \mathrm{~s}$, and extension at $72^{\circ} \mathrm{C}$ for $1 \mathrm{~min}$ ), and a final extension at $72^{\circ} \mathrm{C}$ for $8 \mathrm{~min}$. Fluorescence data were collected during the annealing stage of amplification. The presence of specific amplicon was established when fluorescence signal intensity for each molecular beacon probe exceeded the instrument-defined calculated background noise threshold level, based on the fluorescence parameters for no-template controls. The results obtained on the different treatments were standardized to the constitutive ACT2 (actine) gene expression level.

\section{ACKNOWLEDGMENTS}

We are grateful to C. Chaintreuil, E. Giraud, and B. Dreyfus for providing Bradyrhizobium sp. strain ORS278 and valuable expertise for bacterial cultures. This work was partly supported by grants from the French Institute for Agronomic Research (INRA) for CATMA slide production and hybridization.

\section{LITERATURE CITED}

Cartieaux, F., Thibaud, M. C., Zimmerli, L., Lessard, P., Sarrobert, C., David, P., Gerbaud, A., Robaglia, C., Somerville, S., and Nussaume, L. 2003. Transcriptome analysis of Arabidopsis colonized by a plantgrowth promoting rhizobacterium reveals a general effect on disease resistance. Plant J. 36:177-188.

Chaintreuil, C., Giraud, E., Prin, Y., Lorquin, J., Gillis, A., de Lajudie, P., and Dreyfus, B. 2000. Photosynthetic bradirhizobia are natural endophytes of the African wild rice Oryza breviligulata. App. Environ. Microbiol. 66:5437-5447.

Chou, H.-M., Bundock, N., Rolfe, S. A., and Scholes, J. D. 2000. Infection of Arabidopsis thaliana leaves with Albugo candida (white blister rust) causes a reprogramming of host metabolism. Mol. Plant Pathol. 1:99113.

Conrath, U., Beckers, G. J., Flors, V., Garcia-Agustin, P., Jakab, G., Mauch, F., Newman, M.-A., Pieterse, C. M. J., Poinssot, B., Pozo, M.
J., Pugin, A., Schaffrath, U., Ton, J., Wendehenne, D., Zimmerli, L., and Mauch-Mani, B. 2006. Priming: Getting ready for battle. Mol. PlantMicrobe Interact. 19:1062-71.

Crowe, M. L., Serizet, C., Thareau, V., Aubourg, S., Rouze, P., Hilson, P., Beynon, J., Weisbeek, P., van Hummelen, P., Reymond, P., Paz-Ares, J., Nietfeld, W., and Trick, M. 2003. CATMA: A complete Arabidopsis GST database. Nucleic Acids Res. 31:156-8.

De Meyer, G., Capieau, K., Audenaert, K., Buchala, A., Metraux, J.-P., and Höfte, M. 1999. Nanogram amounts of salicylic acid produced by the rhizobacterium Pseudomonas aeruginosa 7NSK2 activate the systemic acquired resistance pathway in bean. Mol. Plant-Microbe Interact. 12:450-458.

Desbrosses, G., Kopka, J., and Udvardi, M. K. 2005. Lotus japonicus metabolic profiling. Development of gas chromatography-mass spectrometry resources for the study of plant-microbe interactions. Plant Physiol. 137:1302-1318.

Duijff, B. J., Pouhair, D., Olivain, C., Alabouvette, C., and Lemanceau, P. 1998. Implication of systemic induced resistance in the suppression of fusarium wilt of tomato by Pseudomonas fluorescens WCS417r and by nonpathogenic Fusarium oxysporum Fo47. Eur. J. Plant Pathol. 104:903-910.

Erban, A., Schauer, N., Fernie, A.R., and Kopka, J. 2007 Non-supervised construction and application of mass spectral and retention time index libraries from time-of-flight GC-MS metabolite profiles. Pages 19-38 in: Metabolomics: Methods and Protocols. W. Weckwerth, ed. Humana Press, Totowa, NJ, U.S.A.

Fiehn O, Kopka J, Dormann P, Altmann T, Trethewey RN, and Willmitzer L. 2000. Metabolite profiling for plant functional genomics. Nature Biotechnol. 18:1157-1161.

Foissac, S., Bardou, P., Moisan, A., Cros, M. J., and Schiex, T. 2003. EUGENE'HOM: A generic similarity-based gene finder using multiple homologous sequences. Nucleic Acids Res. 31:3742-5.

Fowler, T. J., Bernhardt, C., and Tierney, M. L. 1999. Characterization and expression of four proline-rich cell wall protein genes in Arabidopsis encoding two distinct subsets of multiple domain proteins. Plant Physiol. 121:1081-92.

Gaffney, T., Friedrich, L., Vernooij, B., Negrotto, D., Nye, G., Uknes, S., Ward, E., Kessmann, H., and Ryals, J. 1993. Requirement of salicylicacid for the induction of systemic acquired-resistance. Science 261:754756.

Giraud, E., Moulin, L., Vallenet, D., Barbe, V., Cytryn, E., Avarre, J. C., Jaubert, M., Simon, D., Cartieaux, F., Prin, Y., Bena, G., Hannibal, L., Fardoux, J., Kojadinovic, M., Vuillet, L., Lajus, A., Cruveiller, S., Rouy, Z., Mangenot, S., Segurens, B., Dossat, C., Franck, W. L., Chang, W. S., Saunders, E., Bruce, D., Richardson, P., Normand, P., Dreyfus, B., Pignol, D., Stacey, G., Emerich, D., Vermeglio, A., Medigue, C., and Sadowsky, M. 2007. Legumes symbioses: Absence of Nod genes in photosynthetic bradyrhizobia. Science 316:1307-12.

Glazebrook, J. 2001. Genes controlling expression of defense responses in Arabidopsis: 2001 status. Curr. Opin. Plant Biol. 4:301-8.

Gibon, Y., Blaesing, O. E., Hannemann, J., Carillo, P., Hohne, M. Hendriks, J. H., Palacios, N., Cross, J., Selbig, J., and Stitt, M. 2004. A Robot-based platform to measure multiple enzyme activities in Arabidopsis using a set of cycling assays: Comparison of changes of enzyme activities and transcript levels during diurnal cycles and in prolonged darkness. Plant Cell 16:3304-25.

Herbers, K., Mönke, G., Badur, R., and Sonnewald, U. 1995. A simplified procedure for the substractive cDNA cloning of photoassimilateresponding genes: Isolation of cDNAs encoding a new classe of pathogenesis-related proteins. Plant Mol. Biol. 29:1027-1038.

Hilson, P., Small, I., and Kuiper, M. T. 2003. European consortia building integrated resources for Arabidopsis functional genomics. Curr. Opin. Plant Biol. 6:426-9.

Hilson, P., Allemeersch, J., Altmann, T., Aubourg, S., Avon, A., Beynon, J., Bhalerao, R. P., Bitton, F., Caboche, M., Cannoot, B., Chardakov, V., Cognet-Holliger, C., Colot, V., Crowe, M., Darimont, C., Durinck, S., Eickhoff, H., de Longevialle, A. F., Farmer, E. E., Grant, M., Kuiper, M. T., Lehrach, H., Leon, C., Leyva, A., Lundeberg, J., Lurin, C., Moreau, Y., Nietfeld, W., Paz-Ares, J., Reymond, P., Rouze, P., Sandberg, G., Segura, M. D., Serizet, C., Tabrett, A., Taconnat, L., Thareau, V., Van Hummelen, P., Vercruysse, S., Vuylsteke, M., Weingartner, M., Weisbeek, P. J., Wirta, V., Wittink, F. R., Zabeau, M., and Small, I. 2004. Versatile gene-specific sequence tags for Arabidopsis functional genomics: Transcript profiling and reverse genetics applications. Genome Res. 14:2176-89.

Kovàts E. S. 1958. Gas-chromatographische Charakterisierung organischer Ver-bindungen: Teil 1. Retentionsindices aliphatischer Halogenide, Alkohole, Al-dehyde und Ketone. Helv. Chim. Acta 41:1915-1932.

Leeman, M., Van Pelt, J. A., Den Ouden, F. M., Heinsbroek, M., Bakker, P. A. H. M., and Schippers, B. 1995. Induction of systemic resistance by 
Pseudomonas fluorescens in radish cultivars differing in susceptibility to fusarium wilt, using a novel bioassay. Eur. J. Plant Pathol. 101:655664.

Lloyd, J. C., and Zakhleniuk, O. V. 2004. Responses of primary and secondary metabolism to sugar accumulation revealed by microarray expression analysis of the Arabidopsis mutant, pho3. J. Exp. Bot. 55:1221-30.

Lorenzo, O., Piqueras, R., Sanchez-Serrano, J. J., and Solano, R. 2003. ETHYLENE RESPONSE FACTOR1 integrates signals from ethylene and jasmonate pathways in plant defense. Plant Cell 15:165-78.

Lummerzheim, M., De Olivera, D., Castresana, C., Miguens, F. C., Louzada, E., Roby, D., Van Montagu, M., and Timmerman, B. 1993. Identification of compatible and incompatible interactions between Arabidopsis thaliana and Xanthomonas campestris pv. campestris and characterization of the hypersensitive response. Mol. Plant-Microbe Interact. 6:532-544.

Lurin, C., Andres, C., Aubourg, S., Bellaoui, M., Bitton, F., Bruyere, C., Caboche, M., Debast, C., Gualberto, J., Hoffmann, B., Lecharny, A., Le Ret, M., Martin-Magniette, M. L., Mireau, H., Peeters, N., Renou, J. P., Szurek, B., Taconnat, L., and Small, I. 2004. Genome-wide analysis of Arabidopsis pentatricopeptide repeat proteins reveals their essential role in organelle biogenesis. Plant Cell 16:2089-103.

Mantelin, S., Desbrosses, G., Larcher, M., Tranbarger, T. J., Cleyet-Marel, J. C., and Touraine, B. 2006. Nitrate-dependent control of root architecture and $\mathrm{N}$ nutrition are altered by a plant growth-promoting Phyllobacterium sp. Planta 223:591-603.

Martin-Magniette, M. L., Aubert, J., Cabannes, E., and Daudin, J. J. 2005. Evaluation of the gene-specific dye bias in cDNA microarray experiments. Bioinformatics 21:1995-2000.

Mueller, M. J. 1997. Enzymes involved in jasmonic acid biosynthesis. Physiol. Plant 100:653-663.

Murphy, J. F., Reddy, M. S., Ruy, C. M., Kloepper, J. W., and Li, R. 2003. Rhizobacteria-mediated growth promotion of tomato leads to protection against Cucumber mosaic virus. Phytopathology 93:1301-1307.

Nawrath, C., and Metraux, J. P. 1999. Salicylic acid induction-deficient mutants of Arabidopsis express PR-2 and PR-5 and accumulate high levels of camalexin after pathogen inoculation. Plant Cell 11:1393404

Peng X., Wood C. L., Blalock E. M., Chen K. C., Lanfield P. W. and Stromberg A. J. 2003. Statistical implications of pooling RNA samples fro microarray experiments. BMC Bioinformatics 4:26-35.

Persello Cartieaux, F., Nussaume, L., and Robaglia, C. 2003. Tales from the underground: Molecular plant-rhizobacteria interactions. Plant Cell Environ. 26:189-199.

Pieterse, C., Van Wees, S. C., Hoffland, E., Van Pelt, J. A., and Van Loon, L. 1996. Systemic resistance in Arabidopsis induced by biocontrol bacteria is independent of salicylic acid accumulation and pathogenesisrelated gene expression. Plant Cell 8:1225-1237.

Pieterse, C., Van Wees, S. C., Van Pelt, J. A., Knoester, M., Laan, R., Gerrits, H., Weisbeek, P., and Van Loon, L. 1998. A novel signaling pathway controlling induced systemic resistance in Arabidopsis. Plant Cell 10:1571-1580.

Pieterse, C. M. J., Van Pelt, J. A., Ton, J., Parchmann, S., Mueller, M. J., Buchala, A. J., Metraux, J.-P., and Van Loon, L. C. 2000. Rhizobacteriamediated induced systemic resistance (ISR) in Arabidopsis requires sensitivity to jasmonate and ethylene but is not accompanied by an increase in their production. Phys. Mol. Plant Pathol. 57:123-134.

Puskas, L. G., Zvara, A., Hackler, L., Jr., and Van Hummelen, P. 2002. RNA amplification results in reproducible microarray data with slight ratio bias. Biotechniques 32:1330-1334, 1336, 1338, 1340

Roessner, U., Wagner, C., Kopka, J., Trethewey, R.N. and Willmitzer, L. 2000. Technical advance: Simultaneous analysis of metabolites in potato tuber by gas chromatography-mass spectrometry. Plant J. 23, 131-142.

Samson, F., Brunaud, V., Duchene, S., De Oliveira, Y., Caboche, M. Lecharny, A., and Aubourg, S. 2004. FLAGdb++: A database for the functional analysis of the Arabidopsis genome. Nucleic Acids Res. 32:D347-350.

Schilmiller, A. L., and Howe, G. A. 2005. Systemic signaling in the wound response. Curr. Opin. Plant Biol. 8:369-77.

Scholz, M., Gatzek, S., Sterling, A., Fiehn, O., and Selbig, J. 2004. Metabolite fingerprinting: Detecting biological features by independent component analysis. Bioinformatics 20:2447-2454.

Scholz M, Kaplan F, Guy CL, Kopka J, and Selbig J. 2005. Non-linear PCA: A missing data approach. Bioinformatics 21:3887-3895.

Sheen, J., Zhou, L., and Jang, J. C. 1999. Sugars as signaling molecules. Curr. Opin. Plant Biol. 2:410-8.

Stein, M., Dittgen, J., Sanchez-Rodriguez, C., Hou, B.-H., Molina, A., Schulze-Lefert, P., Lipka, V., and Somerville, S. 2006. Arabidopsis PEN3/PDR8, an ATP binding cassette transporter, contributes to nonhost resistance to inappropriate pathogens that enter by direct penetra- tion. Plant Cell 18:731-746.

Stintzi, A., Weber, H., Reymond, P., Browse, J., and Farmer, E. E. 2001. Plant defense in the absence of jasmonic acid: The role of cyclopentenones. Proc. Natl. Acad. Sci. U.S.A. 98:12837-12842.

Thareau, V., Dehais, P., Serizet, C., Hilson, P., Rouze, P., and Aubourg, S. 2003. Automatic design of gene-specific sequence tags for genomewide functional studies. Bioinformatics 19:2191-8.

Taki, N., Sasaki-Sekimoto, Y., Obayashi, T., Kikuta, A., Kobayashi, K., Ainai, T., Yagi, K., Sakurai, N., Suzuki, H., Masuda, T., Takamiya, K., Shibata, D., Kobayashi, Y., and Ohta, H. 2005. 12-oxo-phytodienoic acid triggers expression of a distinct set of genes and plays a role in wound-induced gene expression in Arabidopsis. Plant Physiol. 139:1268-83

Thibaud, M.-C., Gineste, S., Nussaume, L., and Robaglia, C. 2004. Sucrose increases pathogenesis-related PR-2 gene expression in Arabidopsis thaliana through an SA-dependent but NPR1-independent signaling pathway. Plant Physiol. Biochem. 42:81-88.

Thilmony, R., Underwood, W., and He, S. Y. 2006. Genome-wide transcriptional analysis of the Arabidopsis thaliana interaction with the plant pathogen Pseudomonas syringae pv. tomato DC3000 and the human pathogen Escherichia coli O157:H7. Plant J. 46:34-53.

Thimm, O., Blasing, O., Gibon, Y., Nagel, A., Meyer, S., Kruger, P., Selbig, J., Muller, L. A., Rhee, S. Y., and Stitt, M. 2004. MAPMAN: A user-driven tool to display genomics data sets onto diagrams of metabolic pathways and other biological processes. Plant J. 37:914-39.

Ton, J., Pieterse, C. M. J., and Loon, L. C. V. 1999. Identification of a locus in Arabidopsis controlling both the expression of rhizobacteria-mediated induced systemic resistance (ISR) and basal resistance against Pseudomonas syringae pv. tomato. Mol. Plant-Microbe Interact. 12:911-918.

Ton, J., Davison, S., Van Wees, S. C., Van Loon, L., and Pieterse, C. M. 2001. The Arabidopsis ISRI locus controlling rhizobacteria-mediated induced systemic resistance is involved in ethylene signaling. Plant Physiol. 125:652-61.

Ton, J., Van Pelt, J. A., Van Loon, L. C., and Pieterse, C. M. J. 2002. Differential effectiveness of salicylate-dependent and jasmonate/ethylenedependent induced resistance in Arabidopsis. Mol. Plant-Microbe Interact. 15:27-34.

Urbanczyk-Wochniak, E., Baxter, C., Kolbe, A., Kopka, J., Sweetlove, L. J., and Fernie, A. R. 2005. Profiling of diurnal patterns of metabolite and transcript abundance in potato (Solanum tuberosum) leaves. Planta 221:891-903.

Van Hulten, M., Pelser, M., van Loon, L. C., Pieterse, C. M., and Ton, J. 2006. Costs and benefits of priming for defense in Arabidopsis. Proc. Natl. Acad. Sci. U.S.A. 103:5602-7.

Van Loon, L. C., Bakker, P. A., and Pieterse, C. M. 1998. Systemic resistance induced by rhizosphere bacteria. Annu. Rev. Phytopathol. 36:45383.

Van Peer, R., Niemann, G. J., and Schippers, B. 1991. Induced resistance and phytoalexin accumulation in biological control of Fusarium wilt of carnation by Pseudomonas sp. strain WCS417r. Phytopathology 91:728-734.

Van Wees, S. C. M., Pieterse, C. M. J., Trijssenaar, A., Van't Westende, Y A. M., Hartog, F., and Van Loon, L. C. 1997. Differential induction of systemic resistance in Arabidopsis by biocontrol bacteria. Mol. PlantMicrobe Interact. 10:716-724.

Van Wees, S. C., Luijendijk, M., Smoorenburg, I., Van Loon, L., and Pieterse, C. 1999. Rhizobacteria-mediated induced systemic resistance (ISR) in Arabidopsis is not associated with a direct effect on expression of known defense-related genes but stimulates the expression of the jasmonate-inducible gene Atvsp upon challenge. Plant Mol. Biol. 41:537549.

Van Wees, S. C., de Swart, E. A., van Pelt, J. A., van Loon, L. C., and Pieterse, C. M. 2000. Enhancement of induced disease resistance by simultaneous activation of salicylate- and jasmonate-dependent defense pathways in Arabidopsis thaliana. Proc. Natl. Acad. Sci. U.S.A. 97:8711-6.

Verhagen, B. W. M., Glazebrook, J., Zhu, T., Chang, H.-S., van Loon, L. C., and Pieterse, C. M. J. 2004. The transcriptome of rhizobacteriainduced systemic resistance in Arabidopsis. Mol. Plant-Microbe Interact. 17:895-908.

Vincent, J. M. 1970. A Manual for the Practical Study of Root Nodule Bacteria. Blackwell Scientific Publications Ltd., Oxford.

Wang, Y., Ohara, Y., Nakayashiki, H., Tosa, Y., and Mayama, S. 2005. Microarray analysis of the gene expression profile induced by the endophytic plant growth-promoting rhizobacteria, Pseudomonas fluorescens FPT9601-T5 in Arabidopsis. Mol. Plant-Microbe Interact. 18:385-396.

Wagner, C., Sefkow, M., and Kopka, J. 2003. Construction and application of a mass spectral and retention time index database generated from plant GC/EI-TOF-MS metabolite profiles. Phytochemistry 
62:887-900.

Ward, E. R., Uknes, S. J., Williams, S. C., Dincher, S. S., Wiederhold, D. L., Alexander, D. C., Ahl-Goy, P., Metraux, J. P., and Ryals, J. A. 1991. Coordinate gene activity in response to agents that induce systemic acquired resistance. Plant Cell 3:1085-1094.

Whalen, M. C., Innes, R. W., Bent, A. F., and Staskawicz, B. J. 1991. Identification of Pseudomonas syringae pathogens of Arabidopsis and a bacterial locus determining avirulence on both Arabidopsis and soybean. Plant Cell 3:49-59.

Xiao, W., Sheen, J., and Jang, J. C. 2000. The role of hexokinase in plant sugar signal transduction and growth and development. Plant Mol. Biol. 44:451-61.
Yoshida, S., Ito, M., Nishida, I., and Watanabe, A. 2002. Identification of a novel gene HYS1/CPR5 that has a repressive role in the induction of leaf senescence and pathogen-defence responses in Arabidopsis thaliana. Plant J. 29:427-37.

Zimmermann, P., Hirsch-Hoffmann, M., Hennig, L., and Gruissem, W. 2004. GENEVESTIGATOR. Arabidopsis microarray database and analysis toolbox. Plant Physiol. 136:2621-2632.

\section{AUTHOR-RECOMMENDED INTERNET RESOURCES}

CATMA microarrays: www.catma.org Array express: www.ebi.ac.uk/arrayexpress/) 